\title{
A Multidisciplinary Optimization Framework for Control-Configuration Integration in Aircraft Conceptual Design
}

\author{
Ruben E. Perez* and Hugh H. T. Liu \\ University of Toronto, Toronto, ON, M3H 5T6, Canada \\ Kamran Behdinan ${ }^{\ddagger}$ \\ Ryerson University, Toronto, ON, M5B 2K3, Canada
}

\begin{abstract}
The emerging flight-by-wire and flight-by-light technologies increase the possibility of enabling and improving aircraft design with excellent handling qualities and performance across the flight envelope. As a result, it is desired to take into account the dynamic characteristics and automatic control capabilities at the early conceptual stage. In this paper, an integrated control-configured aircraft design sizing framework is presented. It makes use of multidisciplinary design optimization to overcome the challenges which the flight dynamics and control integration present when included with the traditional disciplines in an aircraft sizing process. A commercial aircraft design example demonstrates the capability of the proposed methodology. The approach brings higher freedom in design, leading to aircraft that exploit the benefits of control configuration. It also helps to reduce time and cost in the engineering development cycle.
\end{abstract}

\section{Nomenclature}

$\bar{c} \quad$ mean aerodynamic chord, $\mathrm{ft}$

$\bar{r} \quad$ reference signal

$\bar{u} \quad$ control vector

*Ph.D. Candidate, Institute for Aerospace Studies, and AIAA Student Member

$\dagger$ Associate Professor, Institute for Aerospace Studies, and AIAA Member

$¥$ Associate Professor and Chair, Department of Aerospace Engineering, and AIAA Member 
$\bar{x} \quad$ state vector

$\bar{y} \quad$ output vector

$A \quad$ state matrix

$A R$ aspect ratio

$B$ input matrix

$C \quad$ output matrix

c chord length, $\mathrm{ft}$

$C D$ drag coefficient

$C L \quad$ lift coefficient

ESF engine scaling factor

$f \quad$ objective function

$H Q L$ handling quality level

$I_{y y} \quad$ pitching moment of inertia, slug- $f t^{2}$

$J \quad$ compatibility constraint

$K \quad$ feedback control gain

$M \quad$ pitch moment

MTOW maximum takeoff weight, lb

$n_{z}$ normal acceleration, g's/rad

$p \quad$ roll rate, $\operatorname{deg} / \mathrm{sec}$

$q$ pitch rate, $\mathrm{rad} / \mathrm{sec}$

$r \quad$ yaw rate, $\mathrm{deg} / \mathrm{sec}$

$S \quad$ area, $f t^{2}$

$T$ engine thrust, $\mathrm{lb}$

$t_{p k} \quad$ response peak time, sec

tc thickness to chord ratio

TSFC thrust specific fuel consumption

$V \quad$ aircraft velocity, $\mathrm{ft} / \mathrm{sec}$

$x \quad$ local design variable

y coupling design variable

$Z$ normal force

z global design variable

Subscripts
a aileron
ce control effector
cs control surface
dr dutch roll
e elevator 


$\begin{array}{ll}\text { eng } & \text { engine } \\ h t & \text { horizontal tail } \\ i & i^{\text {th }} \text { discipline } \\ i c & \text { inner chord } \\ \text { oc } & \text { outer chord } \\ r & \text { rudder } \\ r e f & \text { reference value } \\ S L & \text { system level } \\ s p & \text { short period mode } \\ v t & \text { vertical tail } \\ w & \text { wing } \\ w o & \text { washout filter } \\ S y m b o l s & \\ \alpha & \text { angle of attack, rad } \\ \beta & \text { sideslip angle, deg } \\ \delta & \text { deflection, deg } \\ \eta & \text { normalized control effector span location } \\ \Lambda & \text { sweep angle, deg } \\ \lambda & \text { taper ratio } \\ \omega & \text { frequency, rad/sec } \\ \phi & \text { bank angle, deg } \\ \tau & \text { time constant } \\ \varepsilon & \text { constraint tolerance value } \\ \zeta & \text { damping ratio } \\ & \end{array}$

\section{Introduction}

Flight dynamics and control (FD\&C) has a significant impact on the aircraft performance and cost. ${ }^{1}$ It is also an important discipline for flight safety and aircraft certification. Considerations of dynamic characteristics and control design are essential in the design of future aircraft. Furthermore, the use of control-augmented or control-configured vehicles could offer significant opportunities for expanded flight envelopes and enhanced performance, as demonstrated over the years with different research efforts as shown in Figure 1 adapted from Ref. 2.

In the traditional conceptual design process, the disciplinary analyses are performed sequentially. It is an iterative process in which interdisciplinary trades are used to size the aircraft. With the advances of new technologies such as flight-by-wire and flight-by-light 


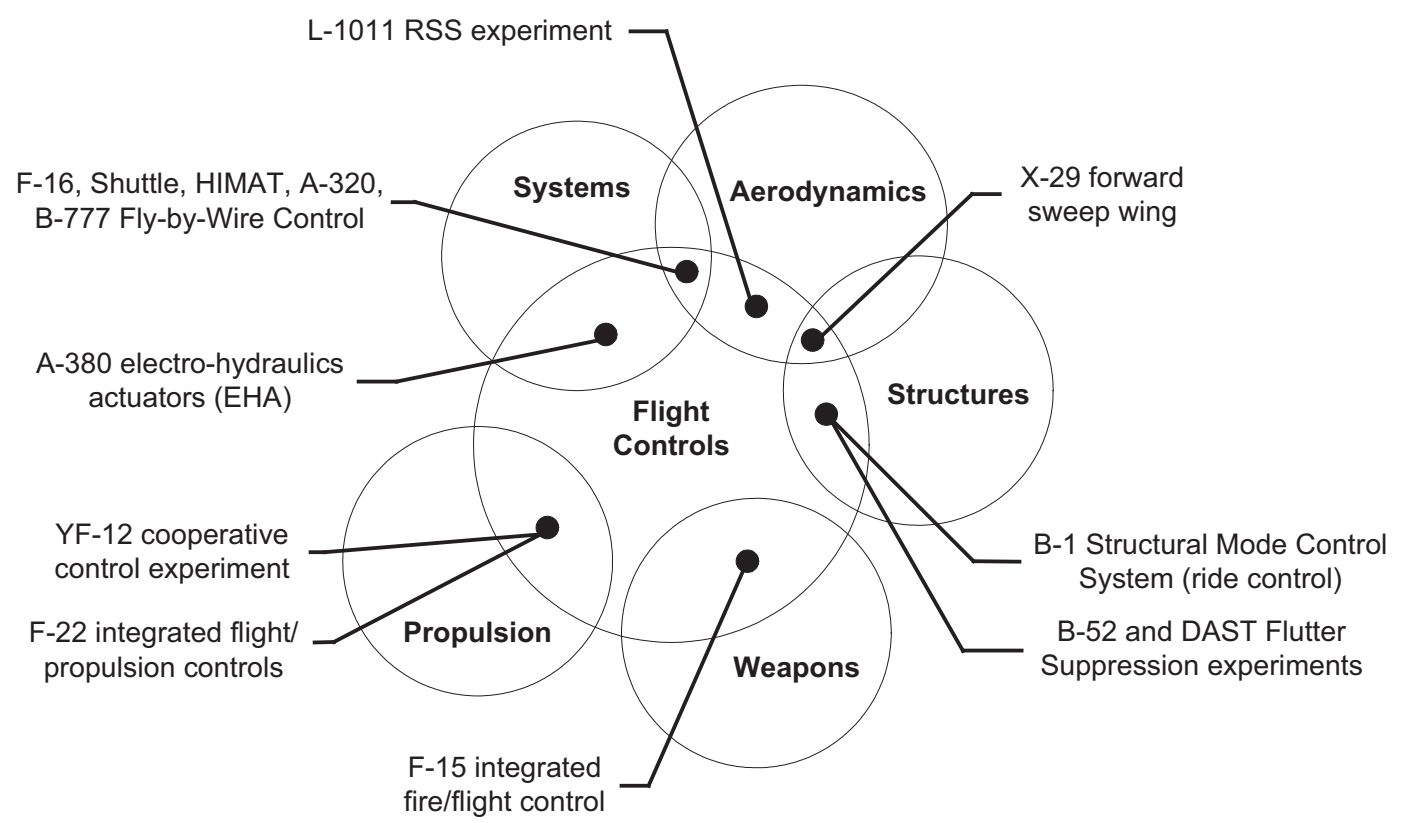

Figure 1. Examples of flight control integration with traditional disciplines

technologies, more emphasis is placed on the analysis of flight dynamics early at the conceptual stage. ${ }^{3,4}$ It is of the authors' main interest to study the impact of the aircraft and control surface sizing on flight control capability and dynamic performance. From flight dynamics and control perspective, the classical control surface sizing at the conceptual design stage is primarily limited to the use of the so-called volume coefficient ${ }^{5}$ which estimates the control surface size based on historical data by assuming the effectiveness of the tail in generating a moment about the center of gravity is proportional to the force (i.e. lift) produced by the tail and its moment arm. ${ }^{6}$ Once these control surfaces are sized, limited trim, control, and stability characteristics can be found using single-degree-of-freedom equations. ${ }^{5,7}$ In most advanced methods such equations are analyzed over some specific set of flight conditions. ${ }^{8,9}$ More explicit considerations of flight dynamics and control are not taken into account until later in the preliminary design stages where much more detailed information about the aircraft has been established.

The challenge is, however, that the sequential process may lead to sub-optimal designs due to its inability to capture the interactions between the sizing of control surfaces, their control system, and their effect on the general dynamic behavior of the aircraft. It does not take into account (or take advantage of) the coupling effects between the sizing and the dynamic characteristics. Also, it imposes constraints on control surfaces and limitations on dynamic and control performance, which may be reflected in costly design modifications at later stages in the design chain. ${ }^{10}$ 
In order to address this challenge, a noval method for the concurrent design of the control system and the aircraft, including the control surface sizing, is presented in this paper. Using a multidisciplinary design optimization (MDO) approach, the control surface sizing with feedback flight control system development is integrated in the conceptual aircraft sizing process. Because more disciplinary aspects of the aircraft are considered simultaneously, better control-augmented aircraft designs can be obtained, based on specified mission parameters, including flight dynamics, handling quality and control related objectives over the entire aircraft mission profile.

\section{Integration Methodology Challenges}

While the benefits of simultaneous considerations of flight dynamics and control in aircraft design have been considered since the 1970s, ${ }^{11}$ very few efforts have been made over the years to integrate FD\&C in the conceptual design phases. A number of challenges are given below.

First of all, the aircraft design has to guarantee satisfactory flight characteristics over the entire flight envelope. In order to ensure positive characteristics, proper control is required for each point within the envelope. The number of analyses required to cover the entire envelope becomes unaffordable at the conceptual stage.

Second, unlike many other disciplines involved in the conceptual design process, FD\&C does not have an obvious figure-of-merit (FOM) that can be used for design optimization. For example, drag count is a continuous FOM used in aerodynamics where the disciplinary goal is to minimize such measurement. The challenge lies in the proper specification definition that considers the dynamics and control requirements and constraints simultaneously.

Third, in the current design process very few interactions between the control and aircraft design processes are taken into account. As a result, when the design has been frozen and information regarding the design matures, so better disciplinary information is known, any deficiencies in FD\&C which could be avoided by considering such interactions suddenly become very expensive to fix; as they requires changes to control surfaces, additional wind tunnel testing to place vortex generators, installation of redundant control systems, etc. The challenge lies in how to enable control-configuration interactions at the conceptual design stage not only to exploit the coupling benefits that arise from such integration but also to reduce any possible FD\&C deficiencies as early as possible.

A final obstacle is how to deal with the increased data and computational complexity. 


\section{Flight Dynamics and Control Integration Methodology}

The proposed methodology makes use of multidisciplinary optimization to solve the design complexity paradigm while simultaneously designing the aircraft and the control system at different constraining conditions. Details of the proposed solution to flight dynamic and control integration challenges are presented in the following subsections.

\section{A. Multidisciplinary Design Integration}

With recent advances in the field of multidisciplinary optimization (MDO), ${ }^{12}$ it is possible to transform the traditional vertical design process into a horizontal process, enabling concurrent analysis and design. Therefore, it is possible to address the FD\&C integration/interaction challenge, and take advantage of the concurrent structure to increase freedom in the design space. Among many different MDO strategies, Collaborative Optimization $(\mathrm{CO})^{13}$ shown in Figure 2 has been found to be one suitable alternative to include flight dynamics and control in the design process. CO is a bi-level optimization scheme that decouples the design process by providing the common design variables and disciplinary coupling interactions all at once in an upper level, eliminating the need for an a priori process that accumulates all the disciplinary data required to perform FD\&C analyses.

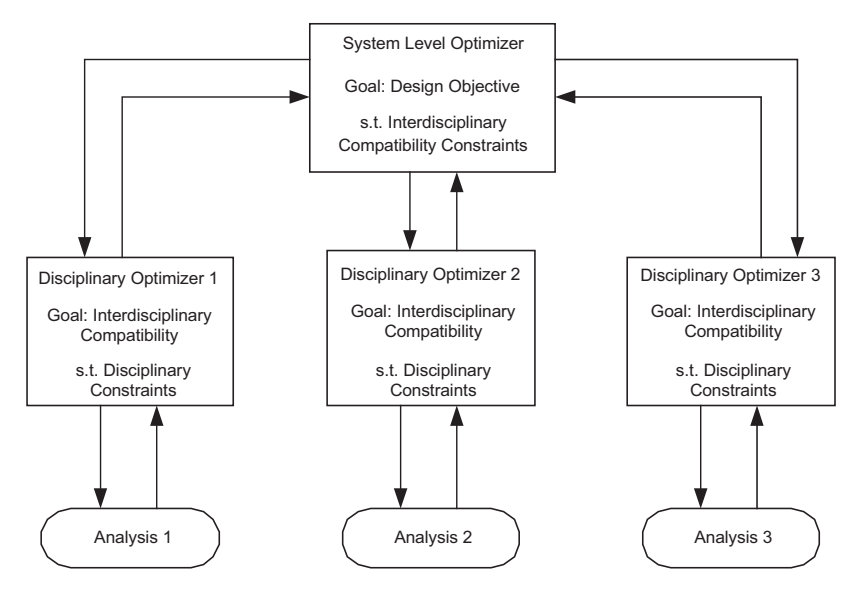

Figure 2. Collaborative Optimization Method

At the system-level (SL), the Collaborative Optimization objective function is stated as:

$$
\begin{aligned}
& \min _{z_{S L}, y_{S L}} f\left(z_{S L}, y_{S L}\right) \\
& \text { s.t. } \quad J_{i}^{*}\left(z_{S L}, z_{i}^{*}, y_{S L}, y_{i}^{*}\left(x_{i}^{*}, y_{j}^{*}, z_{i}^{*}\right)\right) \leq \varepsilon \quad i, j=1, \ldots, n \quad j \neq i
\end{aligned}
$$

where $f$ represents the system level objective function. $J_{i}^{*}$ represents the compatibility 
constraint for the $i^{\text {th }}$ subsystem (of the total $n$ subsystems) optimization problem, and $\varepsilon$ is a constraint tolerance value. Variables shared by all subsystems are defined as global variables $(z)$. Variables calculated by a subsystem and required by another are defined as coupling variables $(y)$. Variables with superscript star indicate optimal values for the subsystem level optimization. Note that the system level constraint assures simultaneous coordination of the coupled disciplinary values. When using local optimization schemes the MDO mathematical foundation leads to a unique 'multidisciplinary feasible point', which is the optimal solution for all disciplines.

The lower level objective function is formulated such that it minimizes the interdisciplinary discrepancy while meeting local disciplinary constraints. At the disciplinary level, the $i^{\text {th }}$ subsystem optimization is stated as:

$$
\begin{aligned}
& \min _{z_{i}, y_{i}, y_{j}, x_{i}} \quad J_{i}=\sum\left(z_{S L_{i}}-z_{i}\right)^{2}+\sum\left(y_{S L_{j}}-y_{j}\right)^{2}+\sum\left(y_{S L_{i}}-y_{i}\right)^{2} \\
& \text { s.t. } \quad g_{i}\left(x_{i}, z_{i}, y_{i}\left(x_{i}, y_{j}, z_{i}\right)\right) \leq 0
\end{aligned}
$$

where $x_{i}$ are local subsystem design variables, $y_{i}$ are subsystem coupling outputs variables, $y_{j}$ are subsystem coupling input variables, $z_{i}$ are the system level variables required by the sub-system discipline analysis, and $g_{i}$ is the specific disciplinary constraint.

FD\&C concurrent evaluation becomes available thanks to the nature of the adopted MDO approach. The flight dynamics and control analysis requires parameters from other disciplines, such as lift, drag, stability derivatives, and inertias. Under the bi-level design structure, these parameters are defined as coupling variables and are provided simultaneously to all disciplines from the system level (see Figure 3). This way, the traditional approach of interdisciplinary trades is avoided. Compatibility between the provided system level information and the calculated disciplinary analysis results is handled by the lower level optimization formulation.

In addition, the MDO bi-level decomposition provides independent and concurrent local disciplinary optimizations processes that can be taken advantage of for control design and to distribute the computational effort when the design process requires analysis at different flight conditions, as shown in Figure 4.

\section{B. FD\&C Design-Constraining Flight Conditions}

In this paper, the critical flight conditions analyses, both symmetric and asymmetric, are defined based on their interdisciplinary effect on the longitudinal and lateral-directional control 


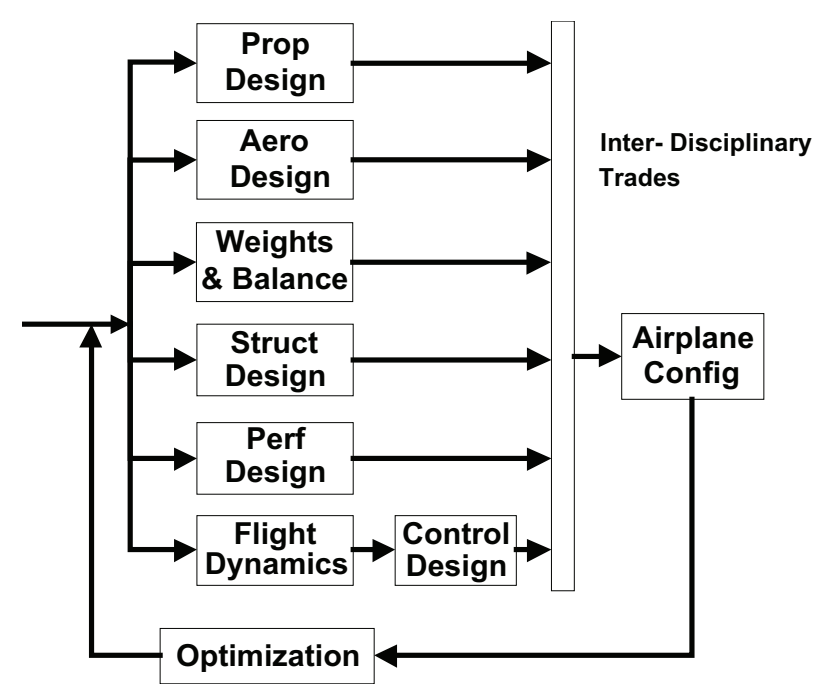

(a) Traditional Design Process (Vertical Development)

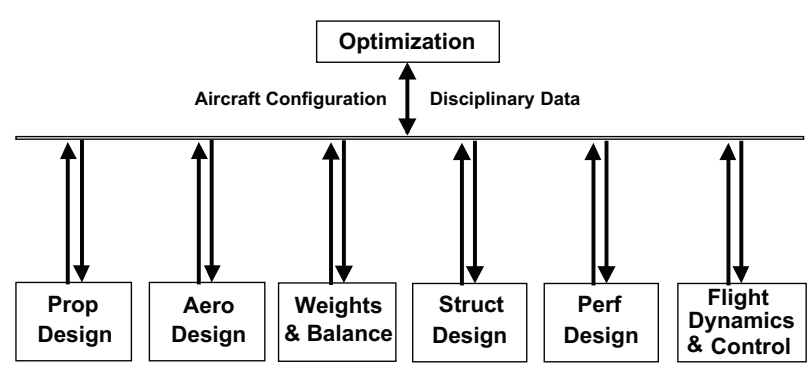

(b) MDO Design Process (Horizontal Development due to Variable Decoupling)

Figure 3. Flight Dynamics and Control Decoupling

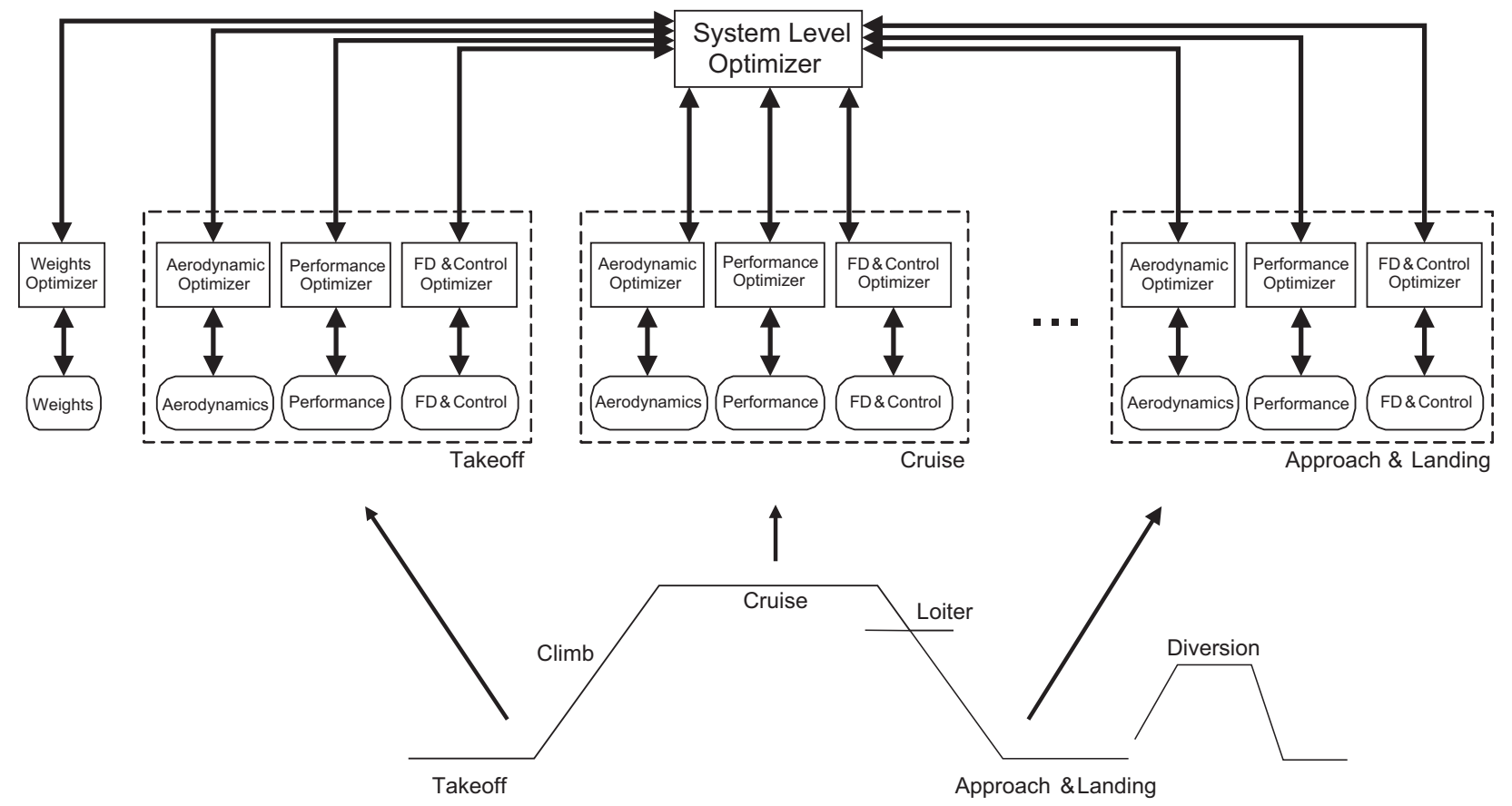

Figure 4. Mission Segments Disciplinary Decomposition 
surfaces sizing as presented in Table 1. They contain static, maneuver, inertia coupling and dynamic considerations along the flight envelope and are valid for a large range of aircraft configuration and concepts. ${ }^{8,14-16}$ Only primary design conditions are considered. Critical control failure cases are neglected since they represent secondary requirements and can be covered in great extent by open-loop and closed-loop dynamic requirements.

Table 1. Longitudinal and Lateral-Directional Design-Constraining Conditions

\begin{tabular}{|c|c|c|c|c|}
\hline $\begin{array}{l}\text { Control Effector } \\
\text { Analysis }\end{array}$ & $\begin{array}{l}\text { Applicable Flight } \\
\text { Conditions }\end{array}$ & $\begin{array}{l}\text { Critical CG } \\
\text { Location }\end{array}$ & $\begin{array}{l}\text { Applicable } \\
\text { Requirement }\end{array}$ & Aircraft Configuration \\
\hline \multicolumn{5}{|c|}{ Longitudinal } \\
\hline 1-g Trim & All & Fwd, Aft & FAR/JAR $25.161 \mathrm{C}$ & Dependent on Flight Condition \\
\hline Approach 1-g Trim & Approach & Fwd & FAR/JAR 25.161C & Full Flaps \\
\hline Landing 1-g Trim & Landing & Fwd & FAR/JAR 25.161C & Full Flaps, Landing Gear Down \\
\hline Go-Around 1-g Trim & Climb & Aft & FAR/JAR 25.161C & Full Flaps, Landing Gear Down \\
\hline Manoeuvre Load & All & Fwd & FAR/JAR 25.255 & Dependent on Flight Condition \\
\hline Go-Around maneuver & Approach & Fwd & FAR/JAR 25.255 & Full Flaps \\
\hline Rotation on Takeoff & Takeoff & Fwd & FAR/JAR 25.143 & $\begin{array}{l}\text { Takeoff Flaps, Landing Gear } \\
\text { Down, in ground effect }\end{array}$ \\
\hline Rotation on Landing & Landing & Aft & FAR/JAR 25.143 & $\begin{array}{l}\text { Full Flaps, Landing Gear Down, } \\
\text { in ground effect }\end{array}$ \\
\hline Dynamic Mode Oscillation & All & Fwd, Aft & FAR/JAR 25.181A & Dependent on Flight Condition \\
\hline \multicolumn{5}{|c|}{ Lateral } \\
\hline Steady Sideslip & All & - & FAR/JAR 25.177 & Dependent of Flight Condition \\
\hline $\begin{array}{l}\text { One Engine Inoperative } \\
\text { Trim }\end{array}$ & All & - & FAR/JAR 25.161 & Dependent of Flight Condition \\
\hline Time to Bank & All & - & FAR/JAR 25.147 & Dependent of Flight Condition \\
\hline $\begin{array}{l}\text { Inertia Coupling (Pitch } \\
\text { due to Velocity Axis Roll) }\end{array}$ & Cruise & - & FAR/JAR 25.143 & Dependent of Flight Condition \\
\hline $\begin{array}{l}\text { Yaw Due to Loaded Roll } \\
\text { Pullout }\end{array}$ & Cruise & - & FAR/JAR 25.143 & Dependent of Flight Condition \\
\hline $\begin{array}{l}\text { Coordinated Velocity Axis } \\
\text { Roll }\end{array}$ & Cruise & - & FAR/JAR 25.143 & Dependent of Flight Condition \\
\hline Dutch Roll Oscillation & All & - & FAR/JAR 25.181B & Dependent of Flight Condition \\
\hline Roll Subsidence & All & - & FAR/JAR 25.181B & Dependent of Flight Condition \\
\hline Spiral Divergence & All & - & FAR/JAR 25.181B & Dependent of Flight Condition \\
\hline Closed-Loop Stability & All & - & FAR/JAR 25.177 & Dependent of Flight Condition \\
\hline
\end{tabular}

Longitudinal static considerations are aimed to maintain steady 1-g level flight, which can become highly demanding for the control effectors at low speeds in both forward (fwd) and aftward (aft) CG limits, and with complex high lift devices (where the aerodynamic pitching moment is large) as is the case in the approach and go-around flight phases. Maneuver considerations include load and rotation capabilities. In the first one the control effectors should be able to achieve load factors between the maximum and minimum operational limits in a pull-up from a dive over the flight envelope. This scenario becomes critical with the maximum takeoff weight and fwd CG, and in the go-around maneuver where the control effectors should be able to provide $8 \mathrm{deg} / \mathrm{sec}^{2}$ pitch acceleration starting from an approach trim condition. Rotation capabilities consider the ability of the control effectors to gener- 
ate enough pitch moment to lift/de-rotate the nose wheel off/on the ground in takeoff and landing respectively. This scenario becomes critical for takeoff at maximum gross weight with fwd CG, and with complex high-lift systems and high CG locations for landing. A pitch acceleration of $7 \mathrm{deg} / \mathrm{sec}^{2}$ for dry, prepared runways is specified for takeoff, it is higher than the minimum requirement as specified by FAR 25.331C, to provide an ample margin of control for future aircraft variants. Longitudinal dynamic response considerations are included as well for both the un-augmented (open-loop) and augmented (closed loop) aircraft. With a control-augmented aircraft the closed-loop dynamic criteria assessment serves primarily for the evaluation of control laws. However, consideration of these conditions during the conceptual sizing stage ensures the aircraft is properly designed for adequate dynamic characteristics where control-augmentation is used to avoid excessive system demands.

For the lateral-directional dynamics, the static considerations include steady sideslip and one-engine-inoperative (OEI) considerations. For the steady sideslip the lateral control surfaces should provide adequate roll and yaw power to perform steady sideslip maneuver at a 10-degree sideslip angle. This situation becomes critical during crosswind landing, when the sideslip angle is the greatest because of low airspeed. Similarly, the roll and yaw control effectors must be able to cope with asymmetric propulsion failure and maintain a steady straight flight with a 5 degree bank angle. This requirement becomes most demanding when operating at very low speed, specifically at takeoff where the weight and inertia are higher. A lateral-directional dynamic consideration is related to the time to bank response to full roll control input where the maneuver result must meet the performance requirements prescribed by Ref. 17. Similar to the longitudinal case, critical dynamic characteristics are considered where the dynamic mode response for both the un-augmented (open-loop) and augmented (closed loop) aircraft is assessed.

Three inertia coupling effects are included as well. The first one considers the pitch due to velocity axis roll, where the control effectors (elevators) should provide sufficient nose-down pitch authority to compensate for the nose-up moment as a result of inertia cross-coupling during high angle-of-attack stability axis roll maneuvers. Similarly, the control effectors (rudder) should possess adequate authority to overcome the yawing moment as a result of inertia coupling during a rolling pullout maneuver. In addition, the control effectors (rudder and ailerons) should be able to maintain a zero sideslip conditions when performing a coordinated stability-axis roll.

Note that many of the above critical conditions for the control effectors match the traditional design mission profile flight phases which greatly simplify the flight condition analyses. However, if necessary other off-mission design conditions can be calculated and taken into consideration in the design process. 


\section{FD\&C Design Constraints and Requirements}

Control power, which describes the efficiency of a control system in producing a range of steady equilibrium or maneuvering states ${ }^{18}$ is defined as the common figure-of-merit to be used in FD\&C. It is quantified in terms of control deflection making it a continuous measurement useful for optimization. Specific sets of flight condition analyses will become critical, as the aircraft geometry varies during sizing. To ensure adequate flight control characteristics, the aircraft has to provide sufficient, yet not excessive, control power to meet the requirements of the prescribed flight analyses. For such reason, the FD\&C disciplinary constraints in 2 are specified in terms of such FOM, along with complementary open and closed loop dynamic requirements. The additional open-loop constraints take care of dynamic response specifications, such as limits of oscillation, damping ratios, natural frequency requirements, and control force gradients, which are defined from military specifications (such as Ref. 17), or certification guidelines (such as FAR or JAR). The closed-loop constraints are mainly aimed to meet with control design requirements in order to achieve internal stability of the control system, reject external disturbances, and assure adequate handling qualities (HQ) requirements for both the longitudinal and lateral-directional modes. The assessment of HQ is closely related to dynamic considerations of the augmented closed-loop aircraft. Different handling qualities quantification procedures exist. For the longitudinal case, the method such as the one proposed in Ref. 19 is very useful for an optimization procedure. It directly quantifies dynamic modes responses with HQ.

For example, if the aircraft dynamics is considered to be uncoupled into longitudinal and lateral modes, the short period mode handling quality can be assessed by using a control anticipation parameter (CAP). This parameter quantifies the response necessary to make precise adjustments to the flight path in terms of instantaneous angular pitching acceleration per unit of steady state normal acceleration. ${ }^{20}$ Furthermore, a generic control anticipation parameter (GCAP) extends the CAP application to both un-augmented and control augmented aircraft. ${ }^{21}$ The GCAP parameter is defined as:

$$
\begin{aligned}
& G C A P=\frac{\dot{q}(0)}{n_{z}\left(t_{p k}\right)}\left(1+\exp \left(\frac{-\zeta_{s p} \pi}{\sqrt{1-\zeta_{s p}^{2}}}\right)\right) \\
& 0<\zeta_{s p}<1
\end{aligned}
$$

where $n_{z}\left(t_{p k}\right)$ is the normal acceleration at the peak time in response to a control step input. Specified GCAP bounds correlate the qualitative HQ levels to the aircraft step input dynamic response. In the case of the Phugoid mode, handling quality is related to the mode damping and time to double amplitude to ensure long enough time to stabilize the aircraft following a disturbance. Lateral HQ include roll and bank oscillations responses, a sideslip excursion and a 'Phi-to-Beta' $(\phi / \beta)$ ratio criteria specifications. ${ }^{17,19}$ 


\section{Control System Design}

While some research has been done to select the most appropriate control system at the design stage before any detailed analysis is performed (see e.g. Ref. 22), the proposed methods do not perform the actual control design, therefore limiting their capability in the scope of control-configured aircraft design. Among the different control systems, the stability augmentation systems (SAS) have the strongest relationship with the design of the airplane, since their use can directly affect the aircraft layout characteristics. For this reason the control design goal at the conceptual design stage is to provide adequate stability augmentation systems to meet the close-loop and handling quality specifications over the flight envelope for both longitudinal and lateral dynamics. The aircraft plant is defined as a strictly proper linear time invariant (LTI) system without disturbances and sensor noise. An output feedback controller, Figure 5, is used to provide the necessary stability augmentation. The feedback control is formulated as:

$$
\begin{aligned}
& \dot{\bar{x}}=A \bar{x}+B \bar{u} \\
& \bar{y}=C \bar{x} \\
& \bar{u}=\bar{r}-K \bar{y} \\
& \text { where }: K=\left[\begin{array}{ccc}
k_{11} & \ldots & k_{1 d} \\
\vdots & \ddots & \vdots \\
k_{c 1} & \ldots & k_{c d}
\end{array}\right]
\end{aligned}
$$

where $\bar{x}$ is the aircraft states, $\bar{y}$ is the plant output, $\bar{u}$ is the control variables, $\bar{r}$ is the reference signal, $c$ is the number of control variables $\bar{u}$, and $d$ is the number of outputs $\bar{y}$, and $A, B, C$ are the state, control and output matrices respectively. The closed-loop system is then:

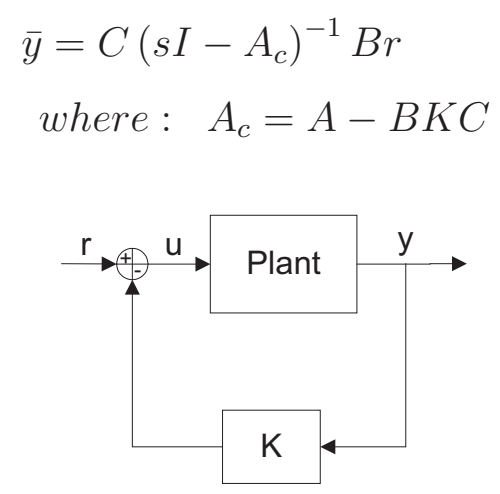

Figure 5. Generalized Control Process

Stability is assured by selecting adequate control gains such that the closed loop system 
lies in the negative real axis. It is assumed the aircraft dynamics follow "traditional" mode responses for both longitudinal and lateral dynamics so the sign of the gains can be selected beforehand to guarantee stabilization. The control design itself is done as part of the MDO lower-level optimization, where control gains are specified as local optimization variables $x$ in (2), while closed-loop stability and control constraints assure proper stabilization and performance.

\section{Application Example}

\section{A. Aircraft Mission and Optimization Goal}

This section illustrates the proposed framework process in the case of a narrow-body 130passenger airliner sizing, with twin wing engines, and conventional aft tail. Its mission profile is specified in Figure 6, in line with industry standards for similarly sized aircraft. The design goal (MDO system level goal, eq. (1)) is to find a feasible aircraft that maximizes specific air range ( $\max _{z_{S L}, y_{S L}}$ Range ) while meeting individual disciplinary requirements as shown in the mission profile. A fixed fuel weight is specified as $40000 \mathrm{lb}$, while the payload weight is specified as $32175 \mathrm{lb}$ based on 130 passengers, crew of 2, and 5 attendants. The subsystem level disciplinary optimization process follow the formulation presented in eq. (2).

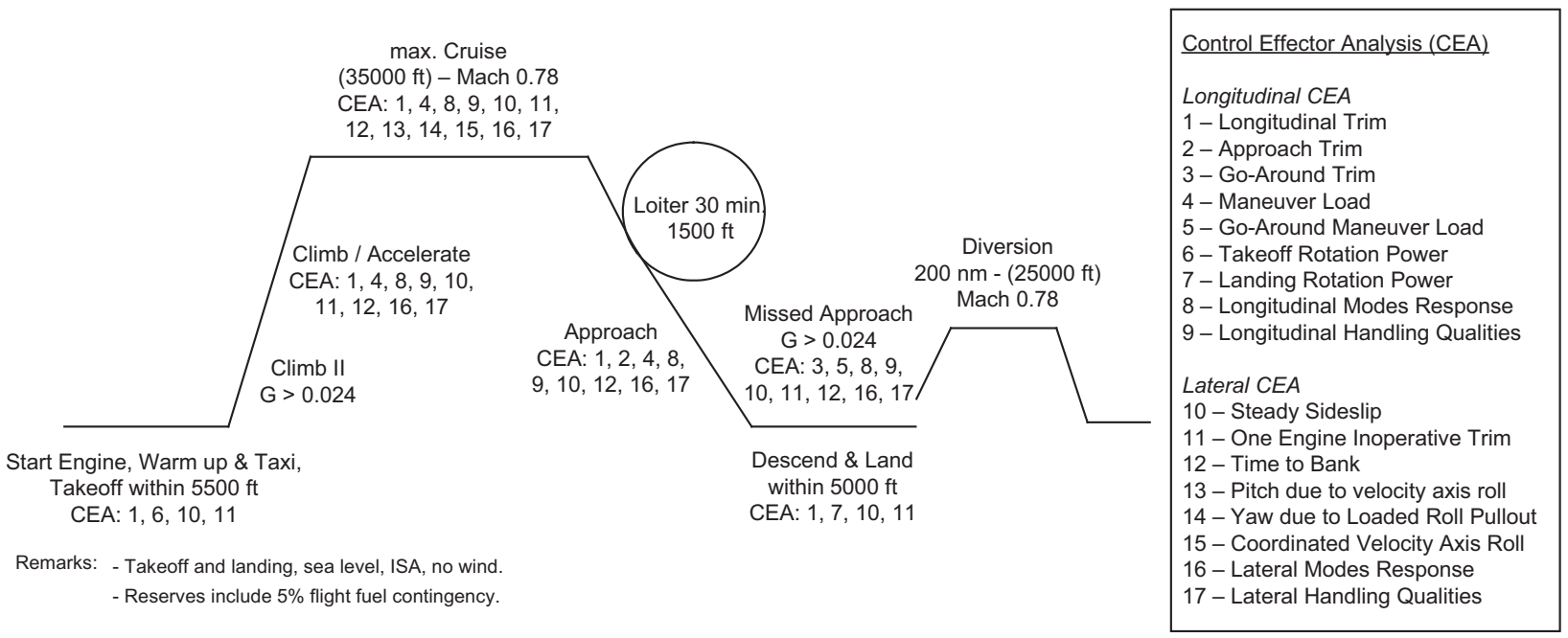

Figure 6. Mission Profile and Longitudinal Control Effectors Analysis Considered

\section{B. Disciplinary Analyses}

The design process of this example is composed of five coupled disciplines, namely: weights, aerodynamics, propulsion, performance, and dynamics \& control. They are coupled as shown 
in the n-square diagram presented in Figure 7. Details of each discipline are described below.

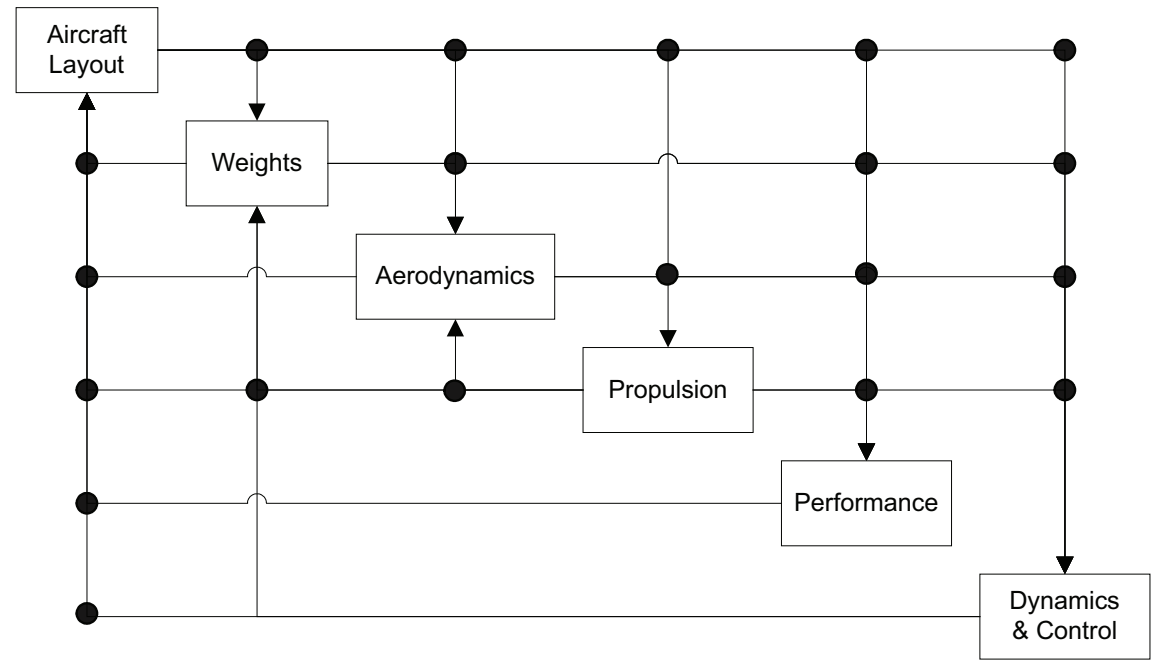

Figure 7. Design Example Disciplinary Couplings

- Weights: The aircraft takeoff weight is calculated from main component weights that are estimated using statistical methods. ${ }^{6,23}$ The maximum permissible center of gravity (CG) range for the configuration is calculated from each aircraft component permissible CG limits, based on their own geometry, physical and functional considerations. ${ }^{24}$ Similarly, the aircraft inertias are calculated from a build-up based on each component inertias calculated from the mean CG location for each component.

- Aerodynamics: Aircraft lift, drag and stability derivatives are calculated based on standard aerodynamic calculation used at the conceptual stage. Induced, parasite and wave drag calculations are considered. The induced drag is calculated from parametric technology models whereas parasite-drag is calculated using a detailed component build$u^{25}$ taking into consideration viscous separation and components mutual interference effects. Transonic wave drag is modeled based on Lock's empirical approximation, using the Korn equation extended by Mason to include sweep. ${ }^{26}$ To provide greater flexibility and accuracy in the calculation of aerodynamic characteristics, downwash effects, and stability derivatives, a combination of semi-empirical formulae $e^{27,28}$ and a non-planar multiple lifting surface panel method are implemented.

- Performance: Takeoff and landing distances, rate of climb, and range are calculated based either on analytical expressions or numerical simulations. For example, takeoff distance is calculated based on a numerical simulation, while specific air range is 
calculated based on Breguet's equation. Landing field length is calculated assuming a landing weight of $90 \%$ MTOW.

- Propulsion: Propulsion characteristics, such as engine weight, thrust and specific fuel consumption for a given altitude and Mach number, are calculated based on engine scaling of a baseline PW-2037 high bypass turbofan engine.

- Flight Dynamics and Control: For the present analysis it is assumed that all aircraft states are measurable without noise. Longitudinal and lateral design open-loop, and closed-loop analyses are performed at each flight mission segment as shown on Figure 6. Control design is performed for all in-flight phases (climb, cruise, and landing approach) of the mission profile.

\section{Control Systems Design}

In this example, the stability augmentation system uses standard cascaded SISO gains for the longitudinal and lateral-directional modes as shown in Figure 8.

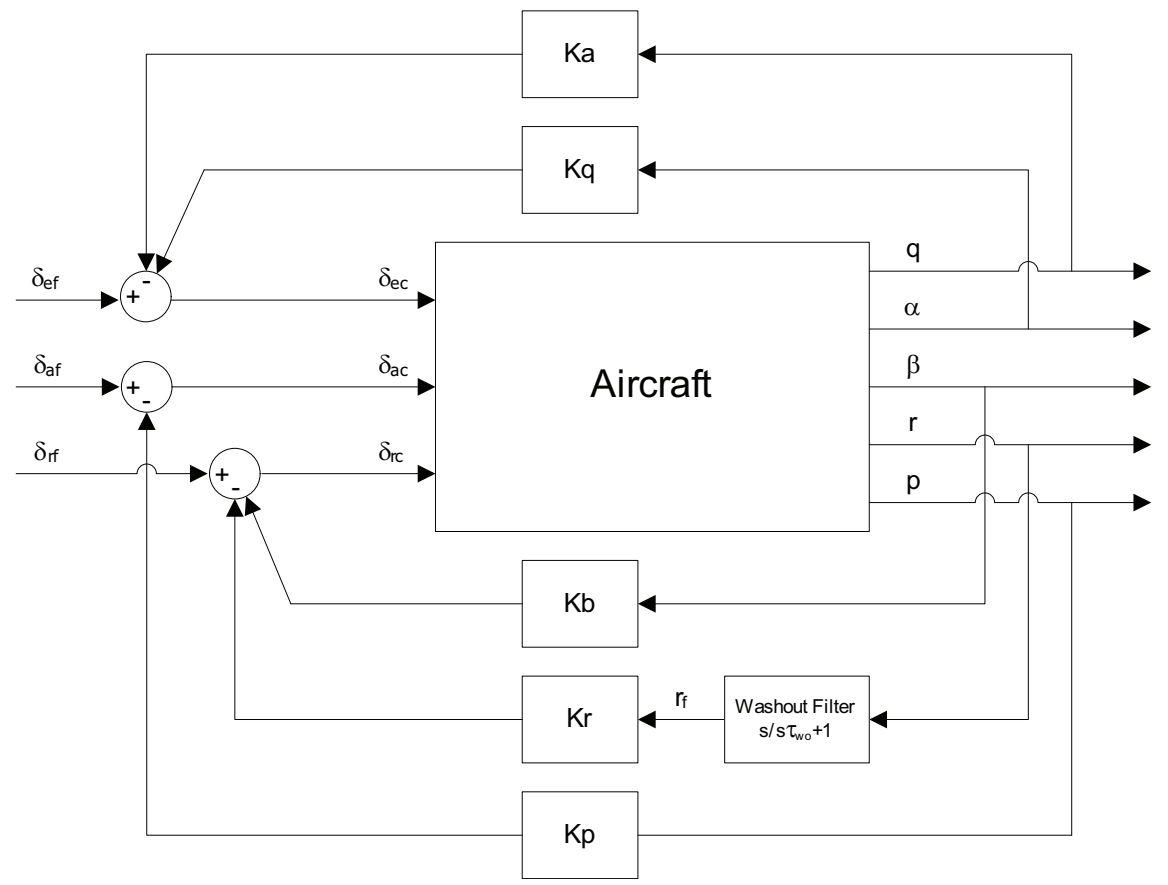

Figure 8. Designed Stability Augmentation System

\section{Longitudinal Stability Augmentation}

Among the longitudinal modes the short period response is of prime concern due to its rapid response and its correlation with handling qualities evaluation. For this reason, efforts 
are concentrated in designing the stability augmentation system (SAS) of this mode. The longitudinal short period flight dynamics equations can be formulated as: ${ }^{29}$

$$
\left[\begin{array}{c}
\dot{\alpha} \\
\dot{q}
\end{array}\right]=\left[\begin{array}{cc}
Z_{\alpha / V} & 1 \\
M_{\alpha}+M_{\dot{\alpha}} Z_{\alpha / V} & M_{q}+M_{\dot{\alpha}}
\end{array}\right]\left[\begin{array}{c}
\alpha \\
q
\end{array}\right]+\left[\begin{array}{c}
Z_{\alpha / V} \\
M_{\delta}+M_{\dot{\alpha}} Z_{\delta} / V
\end{array}\right]\left[\delta_{e}\right]
$$

where $\alpha$ and $q$ are the angle of attack and pitch rate respectively, $\left[\begin{array}{cccc}M_{\alpha} & Z_{\alpha} & M_{\dot{\alpha}} & M_{q}\end{array}\right]$ and $\left[\begin{array}{ll}M_{\delta_{e}} & Z_{\delta_{e}}\end{array}\right]$ are the dimentional stability derivatives and control derivatives respectively; their formulation include the inertia terms, i.e. $M_{\alpha}=\frac{q S_{r e f} \bar{c}}{I_{y y}} \frac{\partial C_{m}}{\partial \alpha}$.

Every dynamic state is affected by the elevator deflection control input signal. The control system is designed to achieve Level I handling qualities performance while meeting natural damping and frequency limit characteristics. The output feedback gains can be expressed as:

$$
\{\bar{u}\}=\delta_{e}=\delta_{e_{r}}-\left[\begin{array}{ll}
k_{\alpha} & k_{q}
\end{array}\right]\left[\begin{array}{l}
\alpha \\
q
\end{array}\right]
$$

\section{Lateral-Directional Stability Augmentation}

The lateral flight control system provides lateral/directional stabilization. It consists of a roll feedback and yaw damper implemented to improve the Dutch roll damping. The washout filter time constant in the yaw damper depends on the washout corner frequency $\omega_{w o}$ as:

$$
\frac{1}{\tau_{w o}}=\omega_{w o}=k_{w o} \omega_{n_{d r}}
$$

where $k_{w o}$ is a control design variable representing a percentage of the Dutch roll natural frequency value.

The open-loop lateral dynamics equations are omitted but they follow the standard LTI form state space form given as: $\{\dot{\bar{x}}\}=[A]\{\bar{x}\}+[B]\{\bar{u}\}$ where $\{\bar{x}\}=\left[\begin{array}{llll}\beta & p & \phi & r\end{array}\right]^{T}$ and $\{\bar{u}\}=\left[\begin{array}{ll}\delta_{a} & \delta_{r}\end{array}\right]^{T}$. The lateral output feedback gains can be expressed as:

$$
\{\bar{u}\}=\left[\begin{array}{ll}
\delta_{a} & \delta_{r}
\end{array}\right]^{T}=\left[\begin{array}{ll}
\delta_{a} & \delta_{r}
\end{array}\right]_{r}^{T}-\left[\begin{array}{c}
0 \\
-k_{r} \omega_{w o}
\end{array}\right] x_{5}+\left[\begin{array}{cccc}
0 & k_{p} & 0 & 0 \\
k_{\beta} & 0 & 0 & k_{r} \omega_{w o}
\end{array}\right]\left[\begin{array}{c}
\beta \\
p \\
\phi \\
r
\end{array}\right]
$$

where $x_{5}$ is an additional state that arise from the inclusion of the washout filter in the 
state space representation. Note that as described in III, the closed loop system stability is guaranteed by selecting adequate control gain direction and values.

\section{Design Variables and Constraints}

Table 2 lists the design variables and their bounds used for the optimization. At the system level, 102 design variables are taken into consideration, from which 18 are global design variables and 84 are coupling design variables. The global design variables specify the general aircraft geometric configuration. Coupling variables include four flight condition independent terms (engine scaling factor, MTOW, fuel and engine weights), while the rest are distributed over the different flight conditions. Local variables are specified only to the flight dynamic and control discipline and correspond to the controller design gains (both longitudinal and lateral). Additional aircraft characteristics are provided as fixed parameters to the optimization problem. The nose gear location is assumed to be at $80 \%$ of the nose length: $x L G_{\text {nose }}=0.8 * L_{\text {nose }}$. The main landing gear location is calculated assuming that $8 \%$ of the maximum takeoff weight is applied on the forward wheels to provide sufficient weight on the nose wheel to permit acceptable traction for steering with the CG at its aft limit: $x L G_{\text {main }}=\left(x C G_{a f t}-0.08 * x_{n L G}\right) / 0.92$. The optimization constraints used at the subsystem level are shown in Table 3. They are split based on the analyzed disciplines and flight phase. The aerodynamic constraints are specified to avoid negative aerodynamic compressibility effects. The flight dynamic and control discipline include control power, and flight condition-dependent open and closed loop dynamic constraints. The control power limits are set below the maximum control deflection, to provide allowance for additional control power requirements, such as active control and turbulence disturbance rejection, and a margin of safety for uncertainties on the stability and control derivative calculations. The normalized extension along the main control span $\left(\eta_{i c}\right.$ to $\left.\eta_{o c}\right)$, chord extension $c_{c e} / c_{c s}$, and maximum deflections of the control flapped surfaces are shown in Table 4. The deflections limits are specified to avoid non-linear or undesirable aerodynamic behavior of the flapped surface.

\section{E. Test Cases, Optimizer and Accurancy}

Two illustrative cases are implemented to determine the relative merits of the proposed methodology. The first case optimizes the aircraft with the proposed FD\&C integration. The second case makes use of the same MDO architecture as the first one (disciplines are decoupled and decomposed) but it performs a traditional aircraft design sizing process where no considerations of FD\&C are made except for the use of tail volume coefficients to constrain the horizontal and vertical tail areas. Both cases are optimized from the same initial design point as shown in Table 2. To maintain uniformity in the calculations, a Sequential 
Table 2. Variables names, units, bound and initial points

\begin{tabular}{|c|c|c|c|c|}
\hline Variable Name & Variable Type & Lower Bound & Upper Bound & Initial Design \\
\hline Wing reference area $\left(S_{w}\right), f t^{2}$ & Global & 1000 & 1400 & 1200 \\
\hline Wing aspect ratio $\left(A R_{w}\right)$ & Global & 7 & 11 & 9 \\
\hline Wing taper ratio $\left(\lambda_{w}\right)$ & Global & 0.1 & 0.4 & 0.2 \\
\hline Wing LE sweep angle $\left(\Lambda_{w}\right)$, deg & Global & 25 & 35 & 30 \\
\hline Wing average thickness/chord ratio $\left(t c_{w}\right)$ & Global & 0.08 & 0.12 & 0.1 \\
\hline Wing dihedral angle $\left(\Gamma_{w}\right)$, deg & Global & -2 & 8 & 6 \\
\hline Wing location along fuselage $\left(x r L E_{w}\right)$ & Global & 0.3 & 0.5 & 0.4 \\
\hline Horizontal Tail area $\left(S_{h t}\right), f t^{2}$ & Global & 200 & 350 & 300 \\
\hline Horizontal Tail aspect ratio $\left(A R_{h t}\right)$ & Global & 3 & 5 & 4 \\
\hline Horizontal Tail taper ration $\left(\lambda_{h t}\right)$ & Global & 0.3 & 0.6 & 0.4 \\
\hline Horizontal Tail LE sweep angle $\left(\Lambda_{h t}\right)$, deg & Global & 25 & 40 & 35 \\
\hline Horizontal Tail thickness/chord ratio $\left(t c_{h t}\right)$ & Global & 0.07 & 0.11 & 0.09 \\
\hline Horizontal Tail dihedral angle $\left(\Gamma_{h t}\right)$, deg & Global & -2 & 3 & 0 \\
\hline Vertical Tail area $\left(S_{v t}\right), f t^{2}$ & Global & 200 & 400 & 350 \\
\hline Vertical Tail aspect ratio $\left(A R_{v t}\right)$ & Global & 1.4 & 1.8 & 1.6 \\
\hline Vertical Tail taper ratio $\left(\lambda_{v t}\right)$ & Global & 0.3 & 0.6 & 0.4 \\
\hline Vertical Tail LE sweep angle $\left(\Lambda_{v t}\right)$, deg & Global & 25 & 40 & 40 \\
\hline Vertical Tail thickness/chord ratio $\left(t c_{v t}\right)$ & Global & 0.09 & 0.12 & 0.11 \\
\hline Engine Scaling Factor $(E S F)$ & Global & 0.8 & 1.2 & 1 \\
\hline Maximum takeoff weight $(M T O W), \mathrm{lb}$ & Coupling & 100000 & 155000 & 123200 \\
\hline Engine weight $\left(W_{\text {eng }}\right), \mathrm{lb}$ & Coupling & 5664 & 8670 & 7160 \\
\hline Specific fuel consumption $(T S F C), \mathrm{lb} / \mathrm{hr} / \mathrm{lb}$ & Coupling & 0.20 & 0.80 & 0.50 \\
\hline Engine Thrust $(T), \mathrm{lb}$ & Coupling & 20000 & 35000 & 31000 \\
\hline Maximum Clean Lift Coefficient $\left(C L_{\max }\right)$ & Coupling & 1.30 & 1.50 & 1.47 \\
\hline Lift to Drag Ratio $(L D)$ & Coupling & 6.00 & 15.00 & 9.00 \\
\hline Drag Coefficient $(C D)$ & Coupling & 0.05 & 0.50 & 0.20 \\
\hline Stability Derivative $\left(C z_{\alpha}\right)$ & Coupling & 4.00 & 6.50 & 5.50 \\
\hline Stability Derivative $\left(\mathrm{Cm}_{\alpha}\right)$ & Coupling & -2.00 & 2.00 & -1.20 \\
\hline Stability Derivative $\left(C L_{q}\right)$ & Coupling & 2.00 & 11.00 & 7.00 \\
\hline Stability Derivative $\left(\mathrm{Cm}_{q}\right)$ & Coupling & -40.00 & -10.00 & -20.00 \\
\hline Stability Derivative $\left(\mathrm{Cm}_{\dot{\alpha}}\right)$ & Coupling & -8.00 & -0.10 & -5.70 \\
\hline Stability Derivative $\left(C z_{\delta_{e}}\right)$ & Coupling & 0.05 & 0.50 & 0.33 \\
\hline Stability Derivative $\left(\mathrm{Cm}_{\delta_{e}}\right)$ & Coupling & -2.00 & -0.10 & -1.00 \\
\hline Stability Derivative $\left(C y_{\beta}\right)$ & Coupling & -1.50 & -0.50 & -1.17 \\
\hline Stability Derivative $\left(C l_{\beta}\right)$ & Coupling & -0.30 & -0.10 & -0.26 \\
\hline Stability Derivative $\left(C n_{\beta}\right)$ & Coupling & 0.05 & 0.25 & 0.19 \\
\hline Stability Derivative $\left(C l_{p}\right)$ & Coupling & -0.60 & -0.30 & -0.47 \\
\hline Stability Derivative $\left(C n_{p}\right)$ & Coupling & -0.30 & -0.10 & -0.25 \\
\hline Stability Derivative $\left(C l_{r}\right)$ & Coupling & 0.25 & 0.85 & 0.57 \\
\hline Stability Derivative $\left(C n_{r}\right)$ & Coupling & -0.40 & -0.05 & -0.19 \\
\hline Stability Derivative $\left(C l_{\delta_{a}}\right)$ & Coupling & 0.04 & 0.08 & 0.06 \\
\hline Stability Derivative $\left(C n_{\delta_{a}}\right)$ & Coupling & -0.04 & -0.01 & -0.03 \\
\hline Stability Derivative $\left(C y_{\delta_{r}}\right)$ & Coupling & 0.10 & 0.30 & 0.26 \\
\hline Stability Derivative $\left(C l_{\delta_{r}}\right)$ & Coupling & 0.00 & 0.02 & 0.01 \\
\hline Stability Derivative $\left(C n_{\delta_{r}}\right)$ & Coupling & -0.10 & -0.01 & -0.08 \\
\hline Control gain $\left(k_{\alpha}\right)$ & Local & -0.01 & -50 & 0 \\
\hline Control gain $\left(k_{q}\right)$ & Local & -0.01 & -50 & 0 \\
\hline Control gain $\left(k_{p}\right)$ & Local & 0.01 & 0 & 50 \\
\hline Control gain $\left(k_{\beta}\right)$ & Local & 0.01 & 0 & 50 \\
\hline Control gain $\left(k_{r}\right)$ & Local & -0.01 & -50 & 0 \\
\hline Control variable $\left(k_{w o}\right)$ & Local & 0.3 & 0.2 & 0.4 \\
\hline
\end{tabular}


Table 3. Constraints for the Optimization Problem

\begin{tabular}{|c|c|c|c|}
\hline Discipline & Flight Phase & Constraint Name & Value \\
\hline Geometry & - & Wing span, $\mathrm{ft}$ & $\leq 260$ \\
\hline Geometry & - & Wing LE sweep, deg & $\leq$ H.T. LE sweep \\
\hline Geometry & - & Wing LE edge sweep, deg & $\leq$ V.T. LE edge sweep \\
\hline Weights & - & Avail. wing fuel volume, $f t^{3}$ & $\leq$ Req. block fuel volume \\
\hline Weights & - & CG fwd position \% MAC & $\geq 0.05$ \\
\hline Weights & - & $\mathrm{CG}$ aft position $\% \mathrm{MAC}$ & $\leq 0.55$ \\
\hline Aerodynamics & Climb, Cruise, Approach, Go-Around & Wing Mach divergent drag number & $\geq$ Mach number \\
\hline Aerodynamics & Climb, Cruise, Approach, Go-Around & H.T. Mach divergent drag number & $\geq$ Mach number \\
\hline Aerodynamics & Climb, Cruise, Approach, Go-Around & V.T. Mach divergent drag number & $\geq$ Mach number \\
\hline Performance & Takeoff & Takeoff field Length, ft & $\leq 5500 . \mathrm{ft}$ \\
\hline Performance & Climb & Engine-out climb gradient & $\geq 0.024$ \\
\hline Performance & Go-Around & Missed approach climb gradient & $\geq 0.024$ \\
\hline Performance & Landing & Landing field Length, ft & $\leq 5000 . \mathrm{ft}$ \\
\hline Propulsion & All Flight phases & Drag to Thrust Ratio & $\leq 0.88$ \\
\hline FD\&C & Climb, Cruise, Approach, Go-Around & Static Margin & $\geq 0.05$ \\
\hline $\mathrm{FD} \& \mathrm{C}$ & Takeoff & Rotation elevator power, deg & $\leq 15$ \\
\hline FD\&C & Landing & Rotation elevator power, deg & $\leq 15$ \\
\hline $\mathrm{FD} \& \mathrm{C}$ & Climb, Cruise, Approach, Go-Around & 1-g Trim elevator power, deg & $\leq 15$ \\
\hline $\mathrm{FD} \& \mathrm{C}$ & Climb, Cruise, Approach, Go-Around & Maneuver elevator power, deg & $\leq 15$ \\
\hline FD\&C & Climb, Cruise, Approach, Go-Around & Pitch - Vel. Axis Roll elevator power, deg & $\leq 15$ \\
\hline $\mathrm{FD} \& \mathrm{C}$ & Climb, Cruise, Approach, Go-Around & Steady Sideslip aileron power, deg & $\leq 20$ \\
\hline $\mathrm{FD} \& \mathrm{C}$ & Climb, Cruise, Approach, Go-Around & Steady Sideslip rudder power, deg & $\leq 15$ \\
\hline FD\&C & Climb, Cruise, Approach, Go-Around & Steady Sideslip roll angle, deg & $\leq 5$ \\
\hline $\mathrm{FD} \& \mathrm{C}$ & Climb, Cruise, Approach, Go-Around & Engine-out Trim aileron power, deg & $\leq 20$ \\
\hline FD\&C & Climb, Cruise, Approach, Go-Around & Engine-out Trim rudder power, deg & $\leq 15$ \\
\hline FD\&C & Climb, Cruise, Approach, Go-Around & Yaw - Loaded Roll Pullout, rudder power, deg & $\leq 15$ \\
\hline FD\&C & Climb, Cruise, Approach, Go-Around & Coord. Vel. Axis Roll, aileron power, deg & $\leq 20$ \\
\hline FD\&C & Climb, Cruise, Approach, Go-Around & Coord. Vel. Axis Roll, rudder power, deg & $\leq 15$ \\
\hline $\mathrm{FD} \& \mathrm{C}$ & Climb, Cruise & Open-Loop short period damping ratio & $\geq 0.2, \leq 2.0$ \\
\hline FD\&C & Approach & Open-Loop short period damping ratio & $\geq 0.35, \leq 2.0$ \\
\hline FD\&C & Climb, Cruise, Approach & Open-Loop short period natural frequency & $\geq 1$ \\
\hline FD\&C & Climb, Cruise & Open-Loop short period GCAP for HQL I & $\geq 0.038, \leq 10$ \\
\hline FD\&C & Approach, Go-Around & Open-Loop short period GCAP for HQL I & $\geq 0.096, \leq 10$ \\
\hline $\mathrm{FD} \& \mathrm{C}$ & Climb, Cruise, Approach, Go-Around & Open-Loop dutch roll damping & $\geq 0.02$ \\
\hline FD\&C & Climb, Cruise, Approach, Go-Around & Open-Loop dutch roll natural frequency & $\geq 0.5$ \\
\hline FD\&C & Climb, Cruise, Approach, Go-Around & Open-Loop time to roll, sec & $\leq 3$ \\
\hline FD\&C & Climb, Cruise, Approach, Go-Around & Open-Loop time to double spiral, sec & $\geq 8$ \\
\hline FD\&C & Climb, Cruise & Closed-Loop short period damping ratio & $\geq 0.3, \leq 2.0$ \\
\hline $\mathrm{FD} \& \mathrm{C}$ & Approach, Go-Around & Closed-Loop short period damping ratio & $\geq 0.5, \leq 1.3$ \\
\hline FD\&C & Climb, Cruise, Approach, Go-Around & Closed-Loop short period natural frequency & $\geq 1$ \\
\hline $\mathrm{FD} \& \mathrm{C}$ & Climb, Cruise & Closed-Loop GCAP for HQL I & $\geq 0.3, \leq 3.3$ \\
\hline FD\&C & Approach, Go-Around & Closed-Loop GCAP for HQL I & $\geq 0.16, \leq 3.6$ \\
\hline FD\&C & Climb, Cruise, Approach, Go-Around & Closed-Loop dutch roll damping & $\geq 0.08$ \\
\hline FD\&C & Climb, Cruise, Approach, Go-Around & Closed-Loop dutch roll natural frequency & $\geq 0.5$ \\
\hline $\mathrm{FD} \& \mathrm{C}$ & Climb, Cruise, Approach, Go-Around & Closed-Loop time to roll, sec & $\leq 1.4$ \\
\hline $\mathrm{FD} \& \mathrm{C}$ & Climb, Cruise, Approach, Go-Around & Closed-Loop time to double spiral, sec & $\geq 12$ \\
\hline FD\&C & Climb, Cruise, Approach, Go-Around & Closed-Loop System Eigenvalues & $\leq 0$ \\
\hline
\end{tabular}


Table 4. Control Effector Flapped Surface Characteristics

\begin{tabular}{lcccc}
\hline Control Effector/Parameters & $\eta_{i c}$ & $\eta_{o c}$ & $c_{c e} / c_{c s}$ & max. Deflection, deg \\
\hline \hline Elevator & 0.25 & 0.95 & $30 \%$ & \pm 25 \\
Ailerons & 0.72 & 0.90 & $20 \%$ & \pm 25 \\
Rudder & 0.10 & 1.00 & $26 \%$ & \pm 15 \\
\hline
\end{tabular}

Quadratic Programming (SQP) optimization algorithm ${ }^{30}$ is used at both the system and the disciplinary levels. Proper scaling of the design variables, objectives and constraints is enforced for the gradient-based optimizer to handle discrepancies along the feasible/nearfeasible descent direction when disciplinary constraints force incompatibilities among the different subsystems. Objective function gradients are evaluated using finite differences. Tolerances for the optimization procedure are defined on the order of $10^{-6}$ based on initial studies to have a good compromise between the number of analysis calls at system and subsystem levels and the optimal objective function. Convergence of the optimization procedure is reached when the search direction, maximum constraint violation and first-order optimality measure are less than the specified tolerances.

\section{Results}

\section{A. Optimized Designs and Comparisons}

Table 5 shows selected variables and performance values for the multidisciplinary feasible solution obtained from both the integrated and traditional design test cases. The geometric configuration for both test cases is shown in Figure 9. While similar wing characteristics are obtained for both designs, the horizontal and vertical tail geometry is significantly different as seen in Figure 10. The concurrent consideration of flight dynamics and simultaneous design of stability and control augmentation systems, leads to significant geometric changes over the traditional design approach. The horizontal tail area is reduced to promote lower static margins and improved aerodynamic efficiency. Similarly, the horizontal tail sweep increases to avoid flow separation at high Mach numbers, hence it aggravates changes in wing pitching moment. In addition, the increase in horizontal tail sweep delays the stall angle and produces a more benign non-linear lift/stall behaviour. Furthermore, the wing apex location is slightly moved forward along with a horizontal tail area reduction. This affects the center of gravity of the aircraft and reduces its static margin. At the same time, the designed control system assures the required level of stability is achieved. The wing dihedral is increased significantly to improve roll stability characteristics. In terms of performance, both test cases meet the specified performance requirements. The reduction in exposed surface area for the integrated aircraft design causes higher lift to drag values at all flight conditions, as shown 
in Table 5. An air-range improvement of $510 \mathrm{~nm}$ is reached as compared to the traditional design approach.

Table 5. Traditional and Integrated FD\&C Optimization Results

\begin{tabular}{lll}
\hline Variable Name & Traditional & Integrated FD\&C \\
\hline \hline Wing reference area $\left(S_{w}\right), f t^{2}$ & 1400 & 1400 \\
Wing aspect ratio $\left(A R_{w}\right)$ & 11.00 & 11.00 \\
Wing taper ratio $\left(\lambda_{w}\right)$ & 0.382 & 0.187 \\
Wing LE sweep angle $\left(\Lambda_{w}\right)$, deg & 25.00 & 25.00 \\
Wing average thickness/chord ratio $\left(t c_{w}\right)$ & 0.117 & 0.105 \\
Wing dihedral angle $\left(\Gamma_{w}\right)$, deg & 2.000 & 4.839 \\
Wing location along fuselage $\left(x r L E_{w}\right)$ & 0.39 & 0.35 \\
Horizontal Tail area $\left(S_{h t}\right), f t^{2}$ & 328.43 & 250.35 \\
Horizontal Tail aspect ratio $\left(A R_{h t}\right)$ & 4.88 & 3.07 \\
Horizontal Tail taper ratio $\left(\lambda_{h t}\right)$ & 0.561 & 0.525 \\
Horizontal Tail LE sweep angle $\left(\Lambda_{h t}\right)$, deg & 28.10 & 40.00 \\
Horizontal Tail thickness/chord ratio $\left(t c_{h t}\right)$ & 0.088 & 0.073 \\
Horizontal Tail dihedral angle $\left(\Gamma_{h t}\right)$, deg & 0.00 & -1.97 \\
Vertical Tail area $\left(S_{v t}\right), f t^{2}$ & 250.04 & 250.01 \\
Vertical Tail aspect ratio $\left(A R_{v t}\right)$ & 1.8 & 1.4 \\
Vertical Tail taper ration $\left(\lambda_{v t}\right)$ & 0.40 & 0.60 \\
Vertical Tail LE sweep angle $\left(\Lambda_{v t}\right)$, deg & 31.17 & 40.00 \\
Vertical Tail thickness/chord ratio $\left(t c_{v t}\right)$ & 0.090 & 0.090 \\
Engine Scaling Factor $(E S F)$ & 0.8 & 0.8 \\
Maximum takeoff weight $(M T O W), \mathrm{lb}$ & 120186 & 120413 \\
Engine weight $\left(W_{\text {eng }}\right), \mathrm{lb}$ & 5664 & 5664 \\
Specific fuel consumption $(T S F C)$ @ Cruise, lb/hr/lb & 0.5034 & 0.5034 \\
Engine Thrust $(T)$ @ Takeoff, lb & 25056 & 25056 \\
Maximum Clean Lift Coefficient $\left(C L_{m a x}\right) @$ Cruise & 1.483 & 1.501 \\
Lift to Drag Ratio $(L D) @$ Cruise & 17.050 & 17.653 \\
Drag Coefficient $(C D) @$ Cruise & 0.020 & 0.019 \\
Lift to Drag Ratio $(L D)$ @ Approach & 9.681 & 10.311 \\
Drag Coefficient $(C D) @$ Approach & 0.183 & 0.143 \\
\hline Range, nm & 5278.3 & 5788.7 \\
Takeoff Field Length, ft & 4284.1 & 4261.9 \\
Landing Field Length, ft & 3953.5 & 3945.2 \\
Engine-out climb gradient & 0.0681 & 0.0673 \\
Missed approach climb gradient & 0.0846 & 0.0906 \\
\hline Static Margin @ Cruise & 0.3679 & 0.2424 \\
Static Margin @ Approach & 0.2528 & 0.1992 \\
\hline
\end{tabular}

Table 6 shows a control power requirement comparison between the two design cases, where bold values designate parameters which did not meet the required specifications (Table 3). The integrated design shows reduced static margins due to the horizontal area reduction. The design requires larger elevator deflection for takeoff rotation as compared to the traditional aircraft, but it still within limits of the specified deflection constraint. Trim requirements are similar for both designs. However, the integrated design requires less control power for trim at the approach condition, where the CG is critical at its maximum fwd 


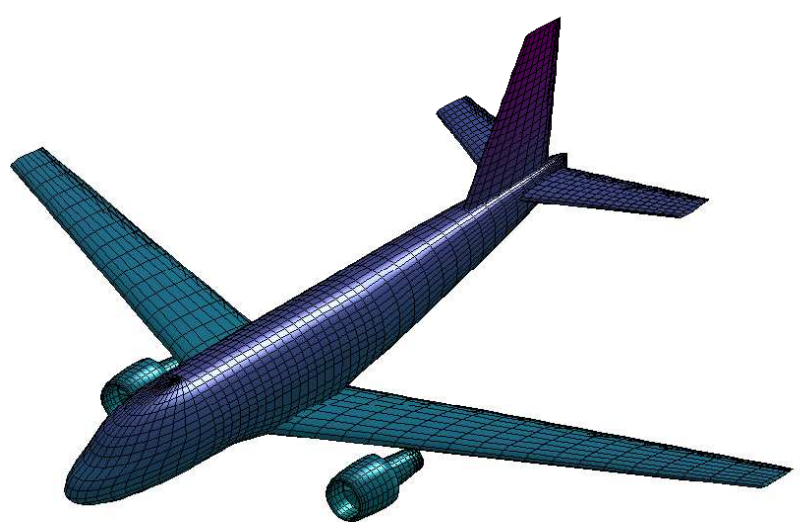

(a) Traditional Design

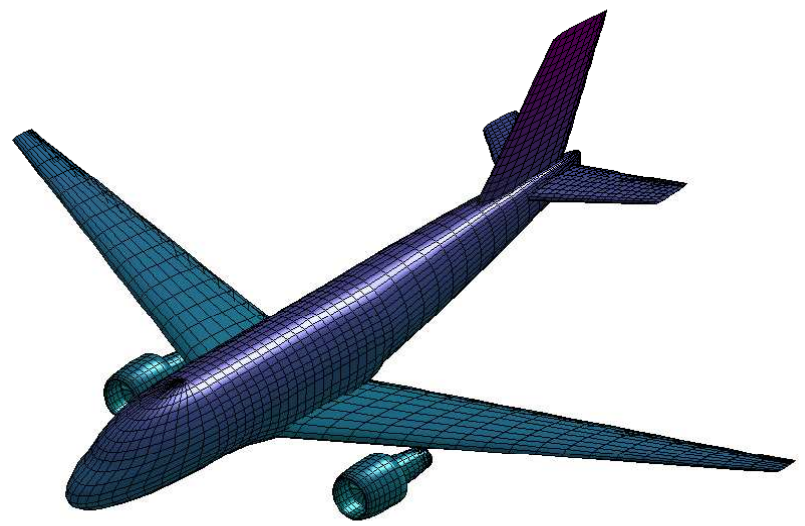

(b) Integrated FD\&C Design

Figure 9. Test Cases Optimal Configurations

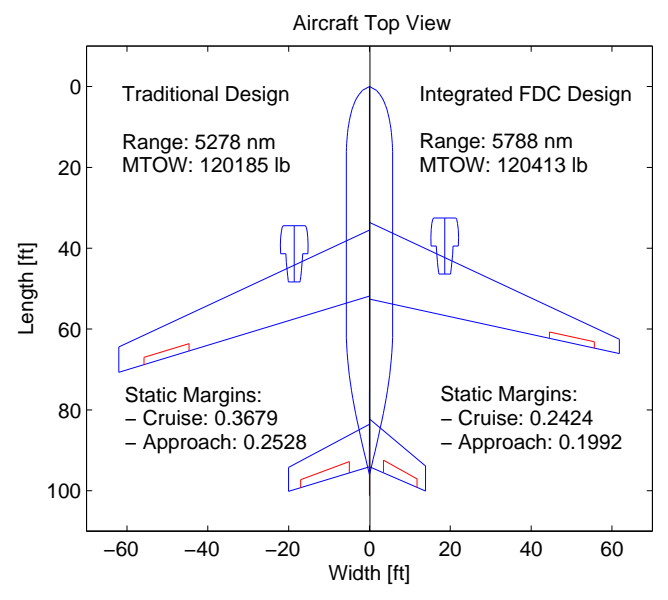

(a) Top View
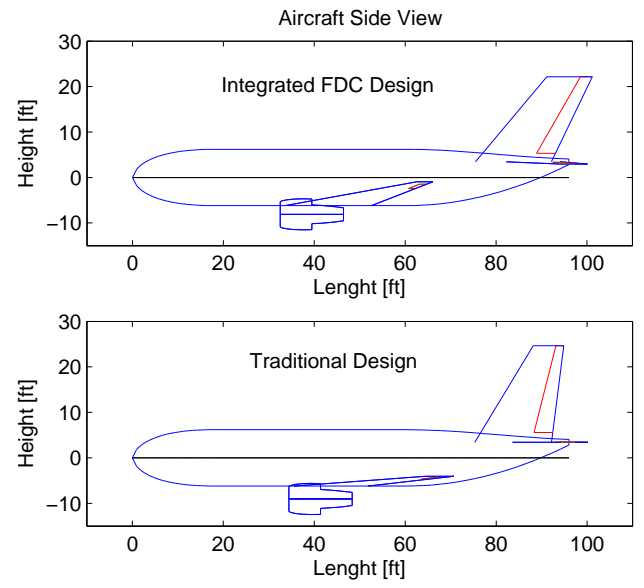

(b) Side View

Figure 10. Aircraft Configuration Comparison 
position. Therefore, it provides a larger control power margin for other tasks such as gust disturbance rejection. For the lateral control power requirements, a significant difference can be seen between the two test cases. The traditional aircraft design approach cannot capture the flight dynamics coupling effects with the general airframe geometric characteristics or take advantage of control-augmentation, leading to poor control power performance. For example, the aileron control power required for sideslip and the rudder control power required for engine-out trim exceeds the maximum allowable deflections at the approach condition. In this case, the aircraft is not able to maintain proper heading tracking when it lands with crosswinds or cope with an asymmetric propulsion failure. These characteristics are not considered directly in the traditional design process. The benefits of the integrated approach become evident since all control power requirements are met from the initial design phase. Furthermore, the required control deflections are lower than the allowable limits providing ample margin of safety to deal with external disturbance rejection or to cope with an increased control effort due to failures. Additional open-loop dynamic results for both aircraft cases are shown in Table 7.

Table 6. Control Power Requirements Comparison

\begin{tabular}{lll}
\hline Parameter & Traditional & Integrated FD\&C \\
\hline \hline Static Margin @ Cruise & 0.3679 & 0.2424 \\
Static Margin @ Approach & 0.2528 & 0.1992 \\
Takeoff Rotation elevator power, deg & -6.2738 & -14.0386 \\
1-g Trim elevator power, deg @ Cruise & 4.3247 & 4.3042 \\
1-g Trim elevator power, deg @ Approach & 19.6754 & 15.0588 \\
Maneuver elevator power, deg @ Cruise & -12.7531 & -12.6707 \\
Pitch - Vel. Axis Roll elevator power, deg @ Cruise & 1.5796 & 2.7342 \\
Pitch - Vel. Axis Roll elevator power, deg @ Approach & 4.0268 & 6.4436 \\
Steady Sideslip aileron power, deg @ Approach & $\mathbf{2 6 . 7 6 7 2}$ & 20.0638 \\
Steady Sideslip rudder power, deg @ Approach & 2.1798 & 6.5533 \\
Steady Sideslip roll angle, deg @ Approach & 4.1680 & 4.2251 \\
Engine-out Trim aileron power, deg @ Approach & 15.6064 & 18.5121 \\
Engine-out Trim rudder power, deg @ Approach & $\mathbf{- 2 8 . 1 8 1 4}$ & -15.0702 \\
Yaw - Loaded Roll Pullout, rudder power, deg @ Approach & $\mathbf{- 3 . 5 7 9 8}$ & -2.6306 \\
Coordinated Velocity Axis Roll, aileron power, deg @ Approach & $\mathbf{2 3 . 3 8 9 5}$ & 16.5668 \\
Coordinated Velocity Axis Roll rudder power, deg @ Approach & $\mathbf{- 4 7 . 8 0 3 7}$ & -13.0146 \\
\hline
\end{tabular}

\section{B. Integrated FD\&C Design Dynamic Behaviour}

Table 8 shows the optimal control gains and closed-loop characteristics of the integrated design. Aircraft flight dynamic characteristics are demonstrated using a simulation of the aircraft dynamics for cruise and landing approach representative conditions with and without the augmentation system. Longitudinal dynamic characteristics are shown in Figure 11 
Table 7. Open-Loop Dynamic Properties Comparison

\begin{tabular}{lll}
\hline Parameter & Traditional & Integrated FD\&C \\
\hline \hline Open-Loop short period damping ratio @ Cruise & 0.3000 & 0.2874 \\
Open-Loop short period damping ratio @ Approach & 0.5272 & 0.4740 \\
Open-Loop short period natural frequency @ Cruise & 2.6409 & 2.1990 \\
Open-Loop short period natural frequency @ Approach & 1.5546 & 1.3677 \\
Open-Loop short period GCAP @ Cruise & 0.5152 & 0.3540 \\
Open-Loop short period GCAP @ Approach & 0.4042 & 0.3294 \\
Open-Loop dutch roll damping @ Cruise & 0.1227 & 0.1247 \\
Open-Loop dutch roll damping @ Approach & 0.1098 & 0.0777 \\
Open-Loop dutch roll natural frequency @ Cruise & 0.8072 & 0.5024 \\
Open-Loop dutch roll natural frequency @ Approach & 1.2906 & 1.2164 \\
Open-Loop time to roll, sec @ Cruise & 0.2725 & 0.2878 \\
Open-Loop time to roll, sec @ Approach & 0.4659 & 0.5842 \\
Open-Loop spiral time to double, sec @ Cruise & 1030.9 & 32.239 \\
Open-Loop spiral time to double, sec @ Approach & 19.5277 & 11.2838 \\
\hline
\end{tabular}

and Figure 12 for the cruise and approach flight phases respectively. On both flight phases, the aircraft shows Level I handling quality for both the bare-airframe and stability augmented system (Figure 11(a), and Figure 12(a)). Other flight conditions present a similar behaviour. The response to an elevator step input by the augmented system is adequate, with fast damping of the disturbance as shown in Figure 11(b) and Figure 12(b).

Table 8. Integrated FD\&C Closed-Loop Characteristics

\begin{tabular}{lll}
\hline Parameter & Cruise & Approach \\
\hline \hline$k_{\alpha}$ & -0.510 & -1.000 \\
$k_{q}$ & -0.610 & -1.000 \\
$k_{p}$ & 1.201 & 1.301 \\
$k_{\beta}$ & 1.021 & 0.001 \\
$k_{r}$ & -0.891 & -0.591 \\
$k_{w o}$ & 0.300 & 0.300 \\
\hline Closed-Loop short period damping ratio & 0.6066 & 0.5755 \\
Closed-Loop short period natural frequency & 2.8929 & 1.8735 \\
Closed-Loop short period GCAP & 0.6004 & 0.5926 \\
Closed-Loop dutch roll damping & 0.1604 & 0.1726 \\
Closed-Loop dutch roll natural frequency & 0.9438 & 0.9591 \\
Closed-Loop time to roll, sec & 0.1164 & 0.3256 \\
\hline
\end{tabular}

In a similar way, the response of the augmented aircraft to an aileron and rudder doublet control inputs are shown in Figure 13 and Figure 14 for the cruise and approach flight phases, respectively. It can be seen that the found lateral control augmentation system provide adequate control in both the roll rate and yaw rates, where the augmented system quickly damps out the commanded oscillations without significant overshoot. 


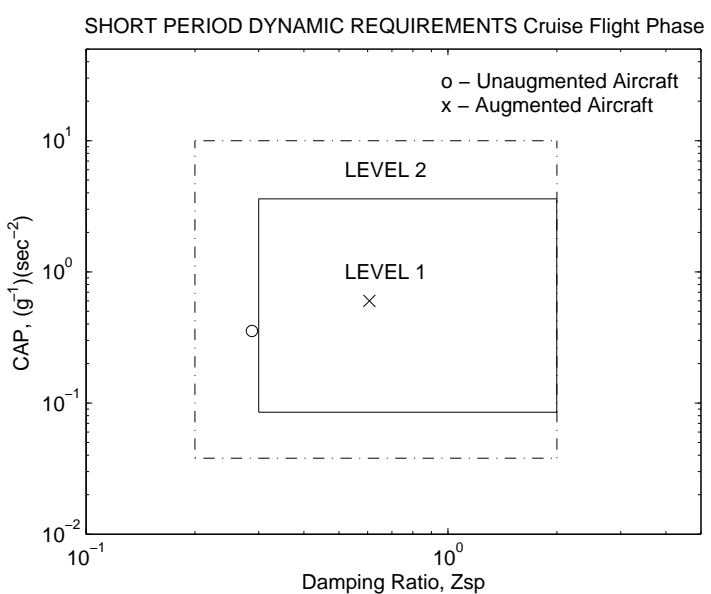

(a) Short-Period Handling Qualities

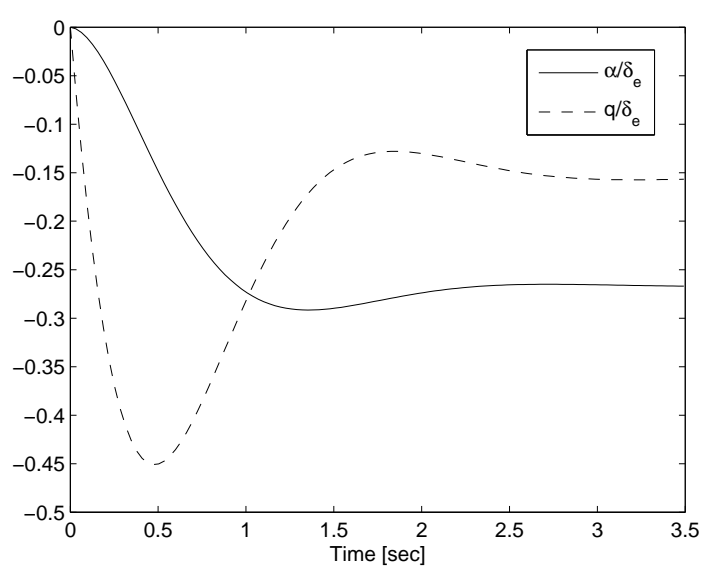

(b) Closed-Loop Response to Control Step

Figure 11. Cruise Longitudinal Dynamics Characteristics

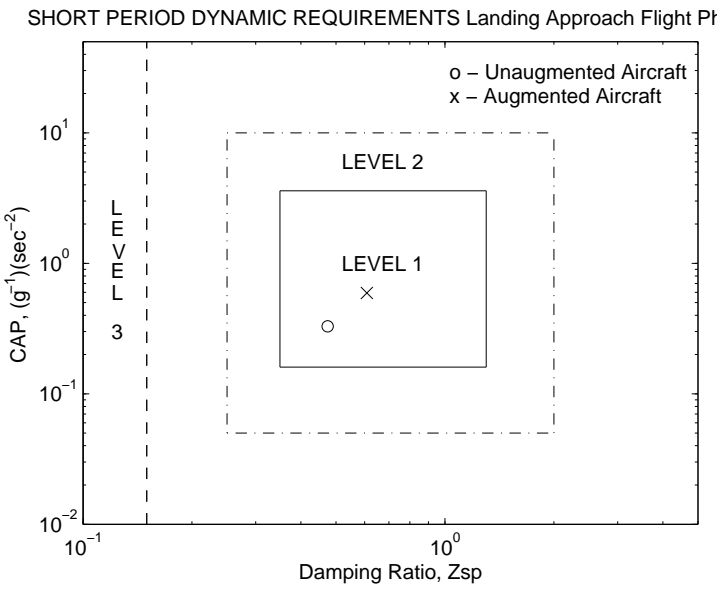

(a) Short-Period Handling Qualities

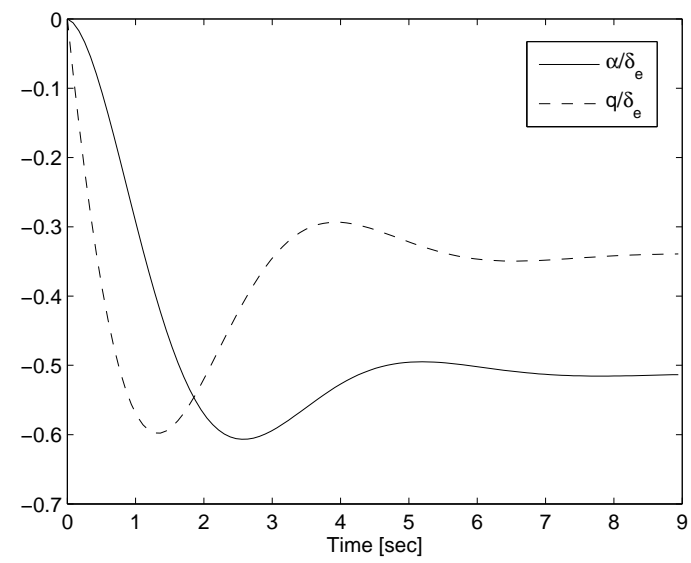

(b) Closed-Loop Response to Control Step

Figure 12. Landing Approach Longitudinal Dynamics Characteristics 

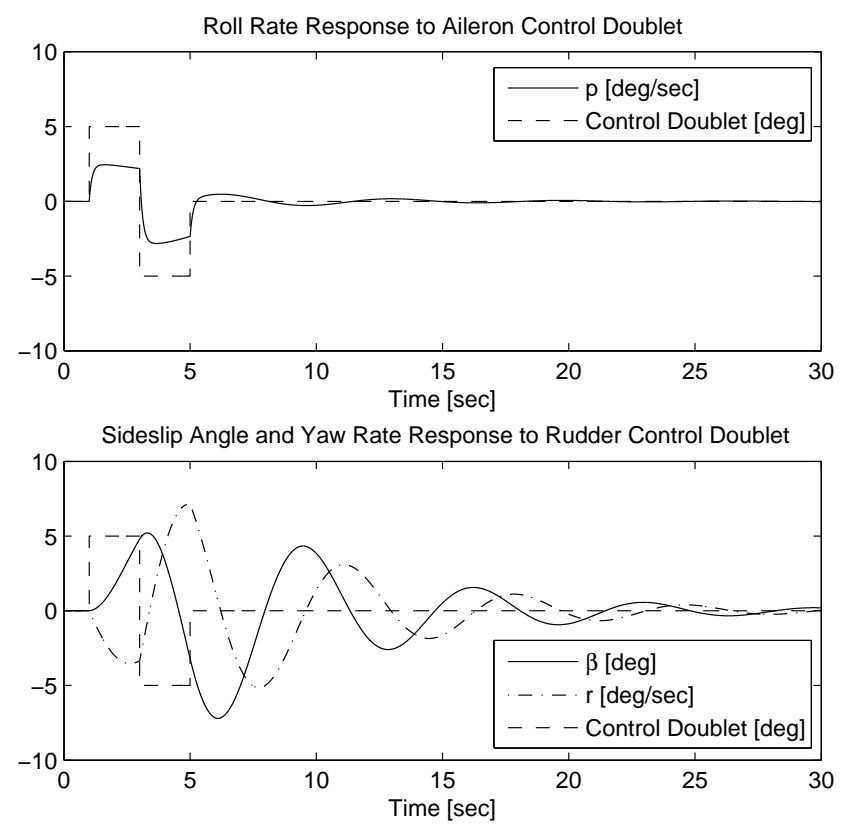

Figure 13. Cruise Closed-Loop Lateral Dynamics Response to Controls Doublet
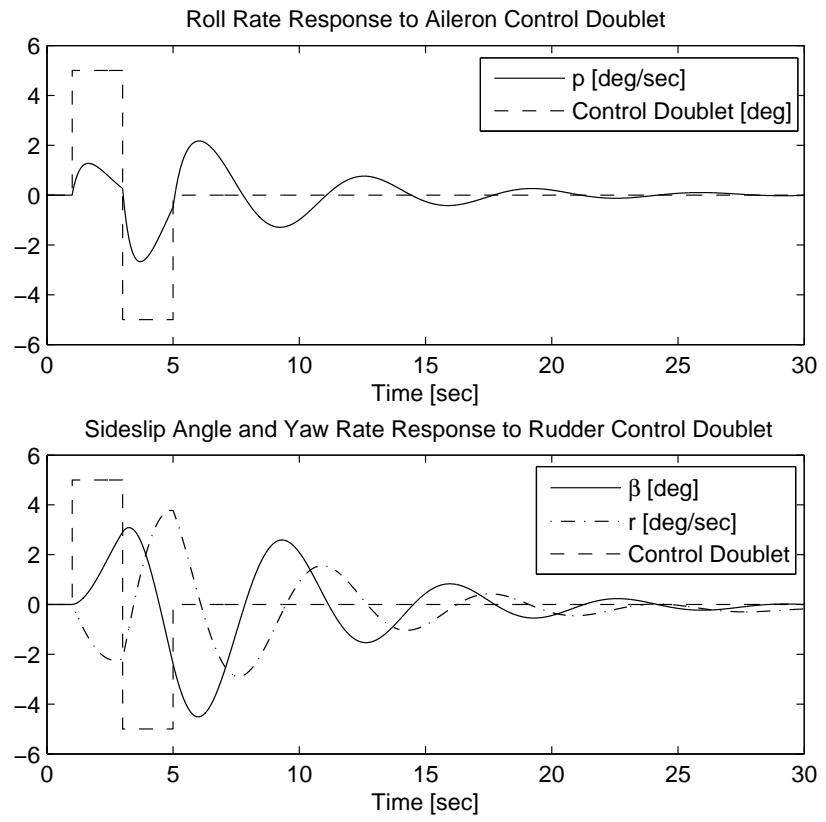

Figure 14. Landing Approach Closed-Loop Lateral Dynamics Response to Controls Doublet 


\section{Size Variation Effect on Integrated Methodology}

The proposed integrated methodology was further applied over a broader set of aircraft sizes for the given configuration example. The aircraft size was varied to accommodate from 70 to 200 passengers. Variables and parameters such as payload and fuel weight were scaled in accordance with the variation of passengers. The effect of the methodology as compared to the traditional sizing process is shown on Figure 15. The integrated approach leads to increase range as compared to the traditional process for all the aircraft size variations analyzed. As before, the integrated designs have reduced total control surface areas while the wing is shifted forward to take advantage of reduced static stability. By taking advantage of control-configuration interactions the design layout is alter to improve performance while meeting the specified disciplinary requirements.

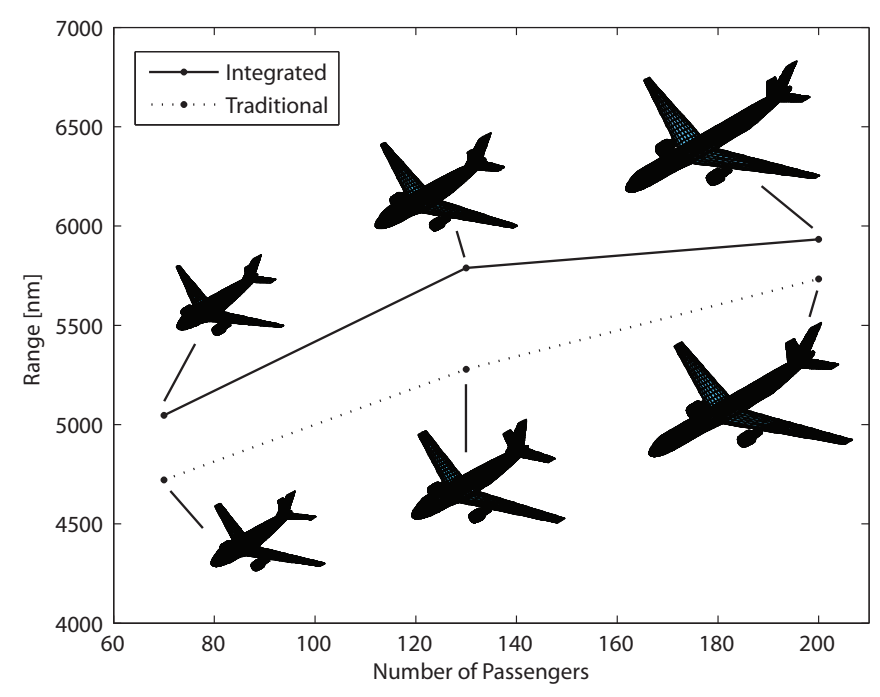

Figure 15. Methodology Effect on Aircraft Size Variation

\section{Conclusions}

A methodology to address the challenges of integrating flight dynamics and control in the aircraft design sizing process has been presented. It enabled control-configuration considerations in the conceptual sizing process, while simultaneously designing proper control augmentation systems. The application of this approach to the design of a commercial aircraft was successful in producing solutions with better performance and flying characteristics than the traditional sizing process over a broad range of aircraft sizes. Furthermore, the methodology could potentially mitigate some of the problems that arise at the later 
stages of the design process as compliance with the most general flight dynamic certification requirements is assured from the conceptual stage, reducing time and cost in the engineering development cycle.

\section{References}

${ }^{1}$ Kehrer, W., "Design Evolution of the Boeing 2707-300 Supersonic Transport," 43rd AGARD Flight Mechanics Panel Meeting, Aircraft Design Integration and Optimization, No. AGARD CP-147, October 1973.

${ }^{2}$ Current State of the Art On Multidisciplinary Design Optimization (MDO), General Publication Series, American Institute of Aeronautics and Astronautics, Washington, DC, January 1991.

${ }^{3}$ Birkenstock, W., "Unstable Aircraft Design: The Computer at the Controls," Flug Revue, Vol. 9, September 1999, pp. 74 .

${ }^{4}$ Dermis, T., Nalepka, J., Thompson, D., and Dawson, D., "Fly-by-Light: The Future of Flight Control Technology," Technology Horizons Magazine, Air Force Research Laboratory Air Vehicles Directorate, , No. Report VA-04-12, April 2005.

${ }^{5}$ Nicolai, L., Fundamentals of Aircraft Design, METS Inc., San Jose, CA, 2nd ed., 1984.

${ }^{6}$ Raymer, D., Aircraft Design: A Conceptual Approach, AIAA Education Series, American Institute of Aeronautics and Astronautics, Washington, DC, 3rd ed., 1999.

${ }^{7}$ Jenkinson, L., Simpkin, P., and Rhodes, D., Civil Jet Aircraft Design, Arnold, London, UK, 1st ed., 1999.

${ }^{8}$ Kay, J., Mason, W., Lutze, F., and Durham, W., "Control Authority Issues in Aircraft Conceptual Design: Critical Conditions, Estimation Methodology, Spreadsheet Assessment, Trim and Bibliography," Tech. Rep. VPI-Aero-200, Virginia Polytechnic Institute and State University, Department of Aerospace and Ocean Engineering, Blacksburg, VA, November 1993.

${ }^{9}$ Chudoba, B., Stability and Control of Conventional and Unconventional Aircraft Configurations - A Generic Approach, Books on Demand GmbH, Norderstedt, Germany, 1st ed., January 2002.

${ }^{10}$ Sahasrabudhe, V., Celi, R., and Tits, A., "Integrated Rotor-Flight Control System Optimization with Aeroelastic and Handling Qualities Constraints," AIAA Journal of Guidance, Control and Dynamics, Vol. 20, No. 2, March-April 1997, pp. 217-224.

${ }^{11}$ Holloway, R. and Burris, P., "Aircraft Performance Benefits from Modern Control Systems Technology," AIAA Journal of Aircraft, Vol. 7, No. 6, Nov-Dec 1970, pp. 550-553.

${ }^{12}$ Sobieszczanski-Sobieski, J., "Multidisciplinary Design Optimization: An Emerging New Engineering Discipline," World Congress of Optimal of Structural Systems, Rio de Janeiro, Brazil, August 1993.

${ }^{13}$ Braun, R., Gage, P., Kroo, I., and J., S.-S., "Implementation and Performance Issues in Collaborative Optimization," 5th AIAA/USAF Symposium on Multidisciplinary Analysis and Optimization, No. Paper 1996-4017, AIAA, Bellevue, WA, September 4-6 1996.

${ }^{14}$ Chudoba, B., "Stability and Control Aircraft Design and Test Condition Matrix," Tech. Rep. Technical Report EF-039/96, Daimler-Benz Aerospace Airbus, Hamburg, Germany, September 1996.

${ }^{15}$ Chudoba, B. and Cook, M., "Identification of Design-Constraining Flight Conditions for Conceptual Sizing of Aircraft Control Effectors," AIAA Atmospheric Flight Mechanics Conference and Exhibit, No. Paper 2003-5386, Austin, TX, August 11-14 2003. 
${ }^{16}$ Steer, A., "Design Criteria For Conceptual Sizing of Primary Flight Controls," The Aeronautical Journal, Vol. 108, No. 1090, December 2004, pp. 629-641.

17 "U.S. Military Handbook MIL-HDBK-1797," Tech. rep., Department of Defense, Washington, DC, December 1997.

${ }^{18}$ Etkin, B. and Reid, L., Dynamics of Flight, Stability and Control, John Wiley \& Sons, New York, NY, 3rd ed., 1996.

${ }^{19}$ Anon, "MIL SPEC - Flying Qualities of Piloted Airplanes," Tech. Rep. MIL-F-8785C, U.S. Government Printing Office, Washington, DC, November 1980.

${ }^{20}$ Bihrle, Jr., W., “A Handling Qualities Theory for Precise Flight Path Control," Tech. Rep. Technical report AFFDL-TR-65-198, Air Force Flight Dynamics Lab., Wright-Patterson AFB, OH, June 1966.

${ }^{21}$ Gautrey, J. and Cook, M., "A Generic Control Anticipation Parameter for Aircraft Handling Qualities Evaluation," The Aeronautical Journal, Vol. 102, No. 1013, March 1998, pp. 151-159.

${ }^{22}$ Anderson, M. and Mason, W., "An MDO Approach to Control-Configured-Vehicle Design," 6Th AIAA/NASA/ISSMO Symposium on Multidisciplinary Analysis and Optimization, No. Paper 1996-4058, Bellevue, WA, September 4-6 1996.

${ }^{23}$ Torenbeek, E., Synthesis of Subsonic Airplane Design, Delft University Press and Kluwer Academic Publishers, Delft, The Netherlands, sixth ed., 1990.

${ }^{24}$ Chai, S., Crisafuli, P., and Mason, W., "Aircraft Center of Gravity Estimation in Conceptual Design," 1st AIAA Aircraft Engineering, Technology, and Operations Congress, No. Paper 95-3882, Los Angeles, CA, September 19-21 1995.

${ }^{25}$ Roskam, J., Airplane Design, Vol. 1-8, DARcorporation, Ottawa, KS, 1st ed., 1998.

${ }^{26}$ Malone, B. and Mason, W., "Multidisciplinary Optimization in Aircraft Design Using Analytic Technology Models," AIAA Journal of Aircraft, Vol. 32, No. 2, March-April 1995, pp. 431-438.

${ }^{27}$ Fink, R., "USAF Stability and Control DATCOM," Tech. rep., Air Force Flight Dynamics Lab., Wright-Patterson AFB, OH, 1975.

${ }^{28}$ Unit, E. E. S. D., "Introduction to Aerodynamic Derivatives Equations of Motion and Stability," Tech. Rep. Item No. 86021, ESDU International plc, London, UK, 1987.

${ }^{29}$ Schmidt, L., Introduction to Aircraft Flight Dynamics, AIAA Education Series, American Institute of Aeronautics and Astronautics, Reston, VA, 1st ed., 1998.

${ }^{30}$ Nocedal, J. and Wright, S., Numerical Optimization, Series in Operational Research, Springer-Verlag, New York, NY, 1st ed., 1999. 